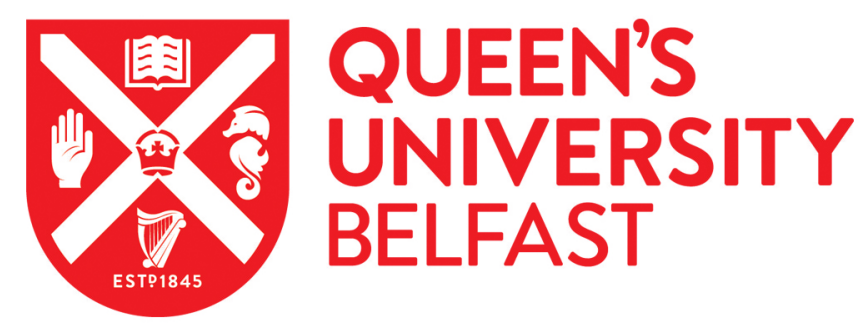

\title{
The effects of oral corticosteroids on lung function, type-2 biomarkers and patient-reported outcomes in stable asthma: a systematic review and meta-analysis
}

Busby, J., Khoo, E., Pfeffer, P. E., Mansur, A. H., \& Heaney, L. (Accepted/In press). The effects of oral corticosteroids on lung function, type-2 biomarkers and patient-reported outcomes in stable asthma: a systematic review and meta-analysis. Respiratory Research.

Published in:

Respiratory Research

Document Version:

Peer reviewed version

Queen's University Belfast - Research Portal:

Link to publication record in Queen's University Belfast Research Portal

\section{General rights}

Copyright for the publications made accessible via the Queen's University Belfast Research Portal is retained by the author(s) and / or other copyright owners and it is a condition of accessing these publications that users recognise and abide by the legal requirements associated with these rights.

\section{Take down policy}

The Research Portal is Queen's institutional repository that provides access to Queen's research output. Every effort has been made to ensure that content in the Research Portal does not infringe any person's rights, or applicable UK laws. If you discover content in the

Research Portal that you believe breaches copyright or violates any law, please contact openaccess@qub.ac.uk. 
1 Title: The effects of oral corticosteroids on lung function, type-2 biomarkers and patient-reported 2 outcomes in stable asthma: a systematic review and meta-analysis

3

4 Authors: John Busby PHD ${ }^{1}$, Esther Khoo ${ }^{1}$, Paul E Pfeffer PHD ${ }^{2}$, Adel H Mansur PhD ${ }^{3}$, Liam G Heaney $5 \quad \mathrm{MD}^{1}$

6

$7 \quad{ }^{1}$ Queen's University Belfast

$8 \quad{ }^{2}$ Barts Health NHS Trust

9 '3niversity Hospitals Birmingham NHS Foundation Trust, and University of Birmingham 10

11 Correspondence: Dr. John Busby, Centre for Public Health, Queens University Belfast, BT12 6BA, 12 john.busby@qub.ac.uk.

13

14 Keywords: Asthma, Prednisolone, Review 


\section{Abstract}

2 Background: Several studies have investigated the physiological effect of OCS in stable asthma,

3

4

5

6

7

8

9

10 however these have included heterogeneous populations and outcomes. This paper is the first to combine their results.

Methods: We searched Medline, Embase and Web of Science databases for studies reporting the impact of OCS on FEV 1 , FVC, blood eosinophils, fractional exhaled nitric oxide (FeNO), Asthma Control Questionnaire (ACQ) score or Asthma Quality Of Life Questionnaire (AQLQ) score in stable asthma. We extracted data on the correlates of OCS response.

Results: 61 studies, comprising 1,608 patients, were included. $\mathrm{FEV}_{1}$ was improved by $9 \%$ (95\% Cl: 7, 11). There were stronger increases in $\mathrm{FEV}_{1}$ among those with a mean baseline $\mathrm{FEV}_{1}<60 \%$ predicted (19\%, 95\% Cl: 13, 24). Despite these improvements, substantial residual impairment remained after treatment. Blood eosinophils were reduced by $76 \%(95 \% \mathrm{Cl}: 63,88)$ with larger decreases in studies of corticosteroid-naïve patients $(93 \%, 95 \% \mathrm{Cl}$ : 73,100$)$. Sputum eosinophils were reduced by $89 \%$ (95\% Cl: 79,98$)$ while FeNO was decreased by $35 \%(95 \% \mathrm{Cl}: 28,41)$. ACQ scores were reduced by $20 \%$ (95\% $\mathrm{Cl}: 11,29)$. Patients with higher baseline lung function impairment, sputum eosinophils, blood eosinophils and FeNO had improved OCS response.

Interpretation: OCS consistently improves lung function, reduces markers of type-2 inflammation, and alleviates asthma symptoms. However, substantial residual impairment remained following treatment and mean improvements were below the minimally important clinically difference. Patients with increased markers of type- 2 inflammation are more responsive to treatment, suggesting these should be used to better target OCS use. 


\section{Background}

2 Asthma is a common condition characterised by symptoms of cough, wheeze and breathlessness and

3

4 accompanied by variable airflow obstruction and bronchial hyperresponsiveness.[1] For most patients inhaled bronchodilator(s) and/or inhaled corticosteroid treatment (ICS) are sufficient to achieve good asthma control[2], although acute exacerbations occur in all severities of asthma[2, 3], and are typically treated with a short course of high-dose oral corticosteroids (OCS) to reduce inflammation and symptoms. A minority of asthmatics do not achieve control with inhaled medications, and may be prescribed maintenance oral corticosteroids to control day-to-day symptoms and reduce exacerbations.[2]

Understanding the physiological effects of OCS is crucial to unpicking the treatment mechanism, weighing up the benefits and risks of treatment escalation prior to OCS initiation, and recognising the expected changes in an adherent patient following OCS commencement. Investigating which patients have the strongest response to OCS treatment has the potential to enable more targeted therapy, and could lead to improved patient outcomes. Several studies have previously investigated the effect of OCS, however these have included heterogeneous populations and explored various outcomes.[4-6] Systematically combining the results of these studies would lead to more complete overview of the OCS effect across all relevant outcomes, more precise estimates of the magnitude of response, and a greater understanding of how and why responses differ across patient populations.

This paper is the first to provide a comprehensive summary of studies investigating the effect of shortcourse or maintenance OCS treatment on lung function, biomarkers of type- 2 inflammation, and patient reported symptoms in stable asthma. A secondary aim is to provide an overview of studies investigating how demographic and clinical characteristics relate to OCS response. 


\section{Search strategy and study selection}

3 We searched the Medline (published since 1946), Embase (published since 1974) and Web of Science databases on $8^{\text {th }}$ November 2018 using search terms related to oral corticosteroids and asthma to identify studies of potential interest. Full details of the electronic search strategy are given in Appendix

6

7 1.

Studies were eligible if they were published in English as peer-reviewed articles. Our review was limited to studies of stable asthma and so we excluded those of patients experiencing an asthma exacerbation (acute asthma) as these can conflate the OCS effect with the natural recovery following an acute episode. Studies using other modes of administration of systemic corticosteroids (e.g. intramuscular or intravenous) were also excluded. Our clinical outcomes of interest were FEV1, FVC, blood eosinophils, FeNO, ACQ and AQLQ. We also extracted details on the most commonly reported measures of Type-2 inflammation: sputum eosinophils, blood eosinophils and FeNO. Titles and abstracts were screened for inclusion by two reviewers (JB and EK) and if deemed relevant according to these criteria, full-text articles were retrieved.

\section{Data extraction and risk of bias assessment}

Two reviewers (JB and EK) extracted data using a standard form. Data were extracted on the study design, intervention offered (e.g. medication name, dose, length), characteristics of patients (e.g. number of subjects, age, gender, maintenance corticosteroid use), and the effect of OCS on study outcomes. We also extracted data on the association between demographic and clinical patient characteristics and OCS response (defined by $\mathrm{FEV}_{1}$ improvement). Study quality was assessed using the Cochrane risk of bias tool for crossover or parallel randomised controlled trials (RCTs).[7] All observational studies were deemed to be at high risk of bias due to the possibility of confounding and lack of treatment allocation blinding. To improve comparability, studies reporting baseline lung function in litres were converted to percent predicted values. We estimated the predicted $\mathrm{FEV}_{1}$ by assuming Caucasian ethnicity and predicting the average height of the study population based on the average age and gender-specific growth charts.[8] RCTs with a non-placebo control arm were analysed as observational before-and-after studies.

\section{Data synthesis and statistical methods}

We summarised the characteristics of studies using descriptive statistics. We calculated the mean difference and its corresponding $95 \%$ confidence interval for each study. Data reported as medians 
1 were treated as means, and inter-quartile ranges used to infer standard errors.[9] Subgroups were combined to calculate an overall study effect and associated standard deviation. [9] When studies did not report standard deviations, we imputed the median from other studies with a similar design (e.g. crossover or before-and-after studies). We presented data as the percentage increase from baseline as this allowed us to combine lung function results reported in both litres and percentage of predicted, and preliminary analysis showed that differing baseline values were a strong contributor to inter-study heterogeneity. This was calculated by dividing the mean difference, and associated $95 \%$ confidence interval, by the study baseline value. Percentage decreases were constrained to be less than $100 \%$.

We assessed statistical heterogeneity using the $I^{2}$ statistic, and used the DerSimonian-Laird randomeffects model used to synthesise data for all study outcomes. We conducted several pre-specified subgroup analysis, investigating the effect of OCS by baseline $\mathrm{FEV}_{1}$, maintenance corticosteroid treatment, age (adult vs. child), asthma stability, intervention dose and risk of bias. We tested for differences between subgroups using the chi-square significance test. We used funnel plots to explore potential small study effects for outcomes comprising at least ten studies.[10] Data were analysed using STATA (version 14). 


\section{Study characteristics}

3

The electronic search identified 12,849 records of which 61 , comprising 1,608 patients, met inclusion criteria (Figure 1). Most studies were from the UK ( $n=23,38 \%$; Table 1$)$ or USA $(n=13,21 \%)$. The majority were observational before and after studies $(n=35,57 \%)$, randomised parallel trials $(n=14$, $n=23 \%)$ or randomised crossover trials $(n=12,20 \%)$. Studies generally included adults (median age $=36.5$, range: $11.6-59.0$ ) and 25 (41\%) had a mean baseline $\mathrm{FEV}_{1}>80 \%$ predicted. Studies investigated the effect of oral prednisolone $(n=56,92 \%)$ methylprednisolone $(n=3,5 \%)$ or dexamethasone ( $n=2,3 \%$ ), with patients most commonly receiving high dose OCS (median: 40mg, IQR: $30,40)$ for around 2 weeks (median: 14 days, IQR: 7, 14).

\section{Lung Function}

$\mathrm{FEV}_{1}$ was improved by $9 \%(95 \% \mathrm{Cl}: 7,11$; Table 2; Figure 2) following OCS, however there was substantial variability across studies $\left(I^{2}=74.6 \%\right)$. Although the vast majority of studies reported gains ( $n=51,96 \%)$, eight (13\%) found increases in excess of $20 \%$ from baseline. Study heterogeneity was reduced, although not negated, in subgroup analysis. We found strong evidence of a larger increase in patients with a baseline $\mathrm{FEV}_{1}$ below $60 \%$ predicted (19\%, 95\% Cl: 13, 24; Appendix 2) compared to an increase of only $5 \%(95 \% \mathrm{Cl}: 3,7)$ in studies of patients with baseline $\mathrm{FEV}_{1}$ in excess of $80 \%$ $\left(p_{\text {subgroup }}<0.001\right)$. There was some evidence of a stronger effect in studies where patients received $40 \mathrm{mg}$ of OCS daily (11\%; $\left.95 \% \mathrm{Cl}: 8,13 ; p_{\text {subgroup }}=0.003\right)$, among studies of patients with uncontrolled asthma (11\%; 95\% Cl: 9, 14; $p_{\text {subgroup }}<0.001$; Appendix 3), and in studies of children aged less than 18 years $\left(12 \% ; 95 \% \mathrm{Cl}: 7,17 ; p_{\text {subgroup }}<0.001\right)$. There was insufficient evidence to conclude differential effects based on maintenance corticosteroid treatment.

Despite the widespread improvements in $\mathrm{FEV}_{1}$ following OCS, significant residual impairment often remained. In the 19 studies of patients with a $\mathrm{FEV}_{1} \%$ less than $80 \%$ at baseline, 14 (74\%) remained below this threshold after OCS treatment. Similar results were found for studies reporting FEV 1 measurements in litres (data not shown). There was no evidence of a placebo effect for FEV ${ }_{1}$, with an overall difference of $1 \%(95 \% \mathrm{Cl}:-1,2)$ in the eleven studies reporting data on patients receiving a placebo.

Overall, FVC increased by $5 \%(95 \% \mathrm{Cl}: 3,7$; Appendix 4) although again, substantial heterogeneity existed across studies $\left(I^{2}=71.1 \%\right)$, with one reporting an extremely large increase of $16 \%$ ( $95 \% \mathrm{Cl}: 10$, 22). There was little evidence of differential effects across study subgroups. 


\section{Correlates of OCS response}

2 Several studies $(n=15)$ investigated the predictors of OCS response on FEV $V_{1}$. Six explored the effect of

3

4 baseline $\operatorname{FEV}_{1}[5,11-15]$, with most reporting negative associations $[5,11,13-15]$ including three that reached statistical significance. $[5,11,15]$ In contrast, a single study reported a substantially higher mean baseline $\mathrm{FEV}_{1}$ among corticosteroid responders (74\%) than non-responders (55\%).[12] A lower $\mathrm{FEV}_{1} / \mathrm{FVC}$ ratio was associated with a stronger OCS response in two studies $[5,13]$, with one reaching statistical significance.[5] Two studies reported that patients with greater bronchodilator reversibility exhibited a stronger OCS response[13, 14], however a further two found little evidence of an effect.[5, 12]

Higher sputum eosinophils were consistently associated with significantly greater OCS response in five studies.[5, 6, 13, 16, 17] Similarly, a strong statistically-significant positive association between blood eosinophils and OCS response was reported in three studies. $[5,6,18]$ Higher baseline FeNO was also associated with a stronger OCS response in three studies[5, 17, 18], although one reported inconclusive results.[12] A smaller number of studies have reported a significantly larger OCS response among CS non-users $(n=2)[14,15]$, patients with higher symptom scores $(n=1)[5]$, and those with later onset asthma ( $n=1)$.[5] There was little evidence that other factors including age $(n=4)[5,12-14]$, smoking status $(n=3)[16,19,20]$, sputum neutrophils $(n=2)[5,13]$, atopy $(n=2)[5,12]$, gender $(n=2)[5$, 12], IGE $(n=1)[12]$ or race $(n=1)[14]$ influenced OCS response.

\section{Biomarkers of type-2 inflammation}

Blood eosinophils were reduced by $76 \%(95 \% \mathrm{Cl}$ : 63 , 88; Figure 3 ) across all studies. Moderate heterogeneity existed between studies $\left(I^{2}=34.1 \%\right)$ with blood eosinophils effectively eradicated $(>95 \%$ reduction) in 4 (40\%) studies. In all but one study (91\%), the mean blood eosinophils following OCS was lower than 150 cells/ $\mu$ l. Further analysis revealed the largest reductions were observed in studies of corticosteroid-naïve patients (93\%, 95\% Cl: 73, 100; Appendix 5), compared to those where at least some patients were taking maintenance ICS $(78 \% ; 95 \% \mathrm{Cl}: 56,100)$ or OCS $(60 \%, 95 \% \mathrm{Cl}: 27,93)$. The smallest reduction of $41 \%(95 \% \mathrm{Cl}: 15,66)$ was observed in a study where all patients were receiving at least $10 \mathrm{mg}$ of maintenance OCS daily.[18]

Sputum eosinophils were reduced by $89 \%$ (95\% Cl: 79 , 98; Figure 3), with decreases of in excess of $80 \%$ reported in eight (80\%) studies. Mean sputum eosinophils were less than $3 \%$ in nine $(90 \%)$ studies following OCS, and less than $1 \%$ in six studies (60\%). There was some inter-study heterogeneity 
$1 \quad\left(I^{2}=15.1 \%\right)$ with one reporting a smaller, although highly uncertain, reduction of $25 \%$ (95\% Cl: -122 , $2100)$ in sputum eosinophils following treatment.

3 Overall, FeNO was reduced by $35 \%$ ( $95 \% \mathrm{Cl}: 28$, 41; Figure 3) after OCS. There was little variation between studies $\left(I^{2}=0 \%\right)$, with the vast majority of study estimates $(n=10 ; 91 \%)$ between a $28 \%$ and $48 \%$ reduction. In all three studies of patients with high baseline FeNO ( $>50 \mathrm{pbb})$, mean values remained substantially elevated (>30ppb) following OCS treatment.

\section{Patient reported outcomes}

All studies $(n=9)$ reported a lower ACQ score following OCS, with an overall reduction of $20 \%(95 \% \mathrm{Cl}$ :

11, 29; Figure 4). In the five studies where patients would be considered uncontrolled at baseline based on an ACQ>1.5, only 1 (20\%) was below this threshold following treatment. Four studies (44.4\%) reported a reduction of at least 0.5 points in the mean ACQ score following OCS. There was moderate heterogeneity $\left(I^{2}=33.4 \%\right)$, however no significant differences were observed between subgroups. Only two studies investigated the effect of OCS on AQLQ, with an overall estimated increase of $6 \%(95 \% \mathrm{Cl}$ : 2, 9; Appendix 6).

\section{Risk of bias and small study effects}

The randomised studies included within the review were generally of very high quality, with 20 (77\%) deemed at low risk of bias (Appendix 7). Four cross-over trials[21-24] were deemed at moderate risk of bias due to insufficient detail on their randomisation procedure. Two studies $[25,26]$ were considered to be at serious risk of bias due to insufficient washout periods of only one week between the intervention and placebo treatment periods. Our conclusions were unchanged when restricting our analyses to studies at low risk of bias however heterogeneity was greatly diminished (Appendix 8). For example, minimal inter-study heterogeneity existed for studies at low risk of bias reporting $\operatorname{FEV}_{1}\left(I^{2}=0.8 \%\right)$ when compared to those at moderate or high risk of bias $\left(I^{2}=80.9 \%\right)$. Estimated increases in $\mathrm{FEV}_{1}$ were higher among studies at a moderate or high risk of bias $(12 \% ; 95 \% \mathrm{Cl}: 9,15)$ than those at low risk of bias $(5 \% ; 95 \% \mathrm{Cl}: 4,7)$ however this was largely driven by these studies recruiting patients with a lower baseline lung function (median baseline FEV ${ }_{1} \%: 67.7 \%$ vs. 83.7\%). These differences were largely eradicated when stratifying by baseline lung function (Appendix 8).

There was some evidence of small study effects in studies investigating change in $\mathrm{FEV}_{1}$ (Appendix 9), with several outlying studies reporting relatively extreme values favouring the effect of OCS, yet these were not replicated for placebo. There was little evidence of small study effects in the funnel plots of 
1 other outcomes; however, this may reflect lower power due to a smaller number of studies (data not 2 shown). 


\section{Discussion}

\section{Summary of main findings}

3

In this first systematic review of patients with stable asthma treated with OCS, comprising 61 studies and 1,608 patients, we found that OCS consistently improved lung function, reduced measures of type-2 inflammation, and improved patient reported-symptoms. We found substantial heterogeneity in the magnitude of $\mathrm{FEV}_{1}$ improvement, although this was largely resolved when restricting to studies at low risk of bias, and was partially explained by a greater response in studies of patients with lower baseline $\mathrm{FEV}_{1}$, with uncontrolled asthma and among those receiving a higher treatment dose. Despite these improvements, there was significant residual impairment in most studies following OCS treatment. Several studies have investigated demographic and clinical predictors of improved OCS response, however consistent associations were only found for patients with higher baseline lung function impairment, sputum eosinophils, blood eosinophils and FeNO.

\section{Lung function}

The mean improvement in $\mathrm{FEV}_{1}$ after OCS was 9\%, however clinicians should expect stronger responses among patients with lower baseline $\mathrm{FEV}_{1}$, unstable asthma or when treating children. Previous work has defined the minimally clinically important difference as $10.4 \%$ for $\mathrm{FEV}_{1}$, suggesting that OCS is likely to lead to a clinically important difference among those with a low baseline FEV ${ }_{1}$ ( $<60 \%$ predicted), but not among those with less severe baseline impairment.[27] Evidence from the studies included in this review demonstrates that patients with increased markers of type-2 inflammation are more responsive to treatment, suggesting that alignment of OCS therapy with an easily measured biomarker could lead to more targeted treatment and improved patient outcomes. The vast majority of studies in our review investigated the effect of relatively short-courses of prednisolone less than 4 weeks duration. However one Turkish study[28] did not find any significant increase in $\mathrm{FEV}_{1}$ after 52 weeks of prednisolone compared to 16 weeks, suggesting that the full benefit of OCS on lung function is realised relatively quickly following OCS initiation. Data from one UK based study of OCS-dependant asthmatics suggests that spirometry measures return to baseline levels around one month post-intervention indicating that the lung function benefits of OCS do not extend long after discontinuation.

\section{Biomarkers of type- 2 inflammation}

In the vast majority of studies, the mean blood eosinophil count was less than 150 cells/ $\mu \mathrm{l}$, FeNO less than 30ppb, and sputum eosinophils less than 3\% following OCS treatment. High levels of these biomarkers have been consistently linked with poor asthma control, suggesting that OCS initiation 
may improve health outcomes in some asthmatics.[29-31] The studies included in this review contained insufficient follow-up to determine the effect of OCS on exacerbations. However, others have previously demonstrated lower exacerbations when patients are managed using strategies targeting reduced biomarkers, suggesting that some reduction in exacerbation risk is possible with OCS use.[32] Blood eosinophils were substantially and consistently reduced by OCS, particularly in patients not receiving maintenance OCS, suggesting that this biomarker can be used to check adherence after OCS initiation if other methods (e.g. prednisolone assays) are unavailable. Data from one UK based study of OCS-dependant asthmatics suggests that type-2 biomarkers return to baseline levels around one month post-intervention demonstrating the strong temporal correlation with OCS use, and confirming their utility as a marker of adherence. Our finding of a profound reduction in blood and sputum eosinophils following OCS, and only a moderate reduction in FeNO, is consistent with OCS being a more potent inhibitor of the IL-5 than IL-4/IL-13 pathway.[33, 34]

\section{Patient reported outcomes}

OCS had a modest effect on patient-reported symptoms, with less than half of studies reporting an improvement in excess of the minimally clinically significant difference of 0.5 ACQ points.[35] Furthermore, studies of uncontrolled patients (based on ACQ score) were rarely adequately controlled following OCS, with mean post-treatment scores remaining above the commonly-used 1.5 score threshold.[36] Data from one UK based study of OCS-dependant asthmatics suggests that patientreported outcomes return to baseline levels around one month post-intervention, suggesting that benefits of OCS on asthma symptoms are not prolonged following treatment withdrawal. Our finding of only moderate improvements in patient reported symptoms in most studies, despite maximal suppression of type-2 inflammation biomarkers, suggests that novel therapies targeting the type-2 cytokine axis are unlikely to prove a panacea in the treatment of refractory disease.

\section{Unanswered questions}

There was no long-term data on the effect of OCS on type-2 biomarker or patient-reported outcomes, and only limited data for lung function. Therefore, it remains unclear if the results we have observed are representative of the benefits that would be seen in patients who are committed to long-term OCS maintenance therapy. Similarly, data on the longer-term trajectory of study outcomes following withdrawal of the OCS was derived from a single study of OCS-dependant asthmatics.[34] It is unclear if these findings can be applied to a broader asthma population on lower levels of maintenance treatment. 
1 Our study did not include patients with acute asthma. However, studies of OCS use in this patient population have also demonstrated significant improvements in $\mathrm{FEV}_{1}$, blood eosinophils and sputum eosinophils following treatment.[37-39] In accordance with our findings, one study in acute asthma found moderate reductions in FeNO following OCS, and concluded that around 4-8 weeks is required for type-2 biomarkers to return to baseline levels after treatment withdrawal.[38] None of the studies included in our review involved patients on biologic therapies; this offers an important area for future research given the increasing availability of these medications.

\section{Strengths and limitations}

Our study is novel, being the first to systematically combine the results from a diverse range of studies exploring the effect of OCS. It provides a comprehensive summary of several important outcomes, and offers an at-a-glance overview which should prove useful to all prescribers of OCS. Combining data from several studies into a single analysis allowed more precise estimates of OCS effect, particularly for FeNO and ACQ score where inter-study heterogeneity was low. Contrasting across all published studies enabled detection of potential small study effects for $\mathrm{FEV}_{1}$. Our narrative summary describing the predictors of OCS response could help enable targeted OCS treatment towards patients who would benefit most.

The primary weakness of our review was the inclusion of observational studies which may have led to increased heterogeneity. Reassuringly, our conclusions were unchanged when restricting to higherquality randomised controlled trials, and there was no evidence of placebo effects for any of our study outcomes. The generalisability of our results may have been reduced through the exclusion of studies investigating acute asthma, and due to the short courses of prednisolone typically investigated. The focus of this review was the physiological benefits of OCS, we did not aim to summarise the evidence of corticosteroid-related morbidity which have been well described in other reviews. $[40,41]$

\section{Conclusions}

Oral corticosteroids consistently improved lung function, reduced markers of type- 2 inflammation, and alleviated asthma symptoms. However, substantial residual impairment remained following treatment and improvements were below the minimally important clinically difference, except for those with substantial baseline impairment. Several factors are associated with OCS response, however substantial heterogeneity remained between studies. These results should lead to more informed use of oral corticosteroids among asthmatics. 


\section{Abbreviations}

2 ACQ: Asthma Control Questionnaire

3 AQLQ: Asthma Quality Of Life Questionnaire

4 FeNO: fractional exhaled nitric oxide

5 FEV: forced expiratory volume

6 FVC: functional vital capacity

7 ICS: inhaled corticosteroid treatment

8 IQR: Inter-quartile range

9 OCS: Oral corticosteroids

10 RCT: randomised controlled trial 
Declarations

2

3 Consent for publication: Not applicable

4

$5 \quad$ Availability of data and materials: Not applicable

6

7 Competing interests: JB, EK and PEP declare no conflicts of interest. AHM received personal and department funds for talks and advisory board meetings and was sponsored to attend national and international conferences from pharmaceutical companies that include GlaxoSmithKline, Astra Zeneca, Novartis, NAPP, Boehringer Ingelheim, Roche, Chiesi. LGH is Academic Lead for the Medical Research Council Stratified Medicine UK Consortium in Severe Asthma which involves industrial partnerships with a number of pharmaceutical companies.

Funding: No funding sources to declare

Authors' contributions: JB designed the study. JB and EK were searched the databases, screened articles for inclusion, extracted study data and analysed the risk of bias. JB analysed the data. JB, EK, PP, AHM, PEP and LGH interpreted the data and drafted the manuscript. All authors reviewed the final manuscript.

Acknowledgements: Not applicable 


\section{References}

[1] S.T. Holgate, Pathogenesis of Asthma, Clinical \& Experimental Allergy 38(6) (2008) 872-897.

[2] C.I. Bloom, F. Nissen, I.J. Douglas, L. Smeeth, P. Cullinan, J.K. Quint, Exacerbation risk and characterisation of the UK's asthma population from infants to old age, Thorax 73(4) (2018) 313-320. [3] R.Y. Suruki, J.B. Daugherty, N. Boudiaf, F.C. Albers, The frequency of asthma exacerbations and healthcare utilization in patients with asthma from the UK and USA, BMC Pulmonary Medicine 17(1) (2017) 74.

[4] S.K. Chhabra, Comparison of a short course of prednisolone with sustained-release theophylline in the control of nocturnal asthma, The Indian journal of chest diseases \& allied sciences 37(1) (1995) 714.

[5] M.H. Kupczyk, S. Middelveld, R. J. M. Dahlen, B. Dahlen, S. E., Phenotypic predictors of response to oral glucocorticosteroids in severe asthma, Respiratory Medicine 107(10) (2013) 1521-1530.

[6] A.R.M. Sousa, R. P. Warnock, L. C. Bolton, S. Hastie, A. Symon, F. Hargadon, B. Marshall, H. Richardson, M. Brightling, C. E. Haldar, P. Milone, R. Chalk, P. Williamson, R. Panettieri, R. Knowles, R. Bleecker, E. R. Wardlaw, A. J., Responsiveness to oral prednisolone in severe asthma is related to the degree of eosinophilic airway inflammation, Clin. Exp. Allergy 47(7) (2017) 890-899.

[7] J.P.T. Higgins, D.G. Altman, P.C. Gøtzsche, P. Jüni, D. Moher, A.D. Oxman, J. Savović, K.F. Schulz, L. Weeks, J.A.C. Sterne, The Cochrane Collaboration's tool for assessing risk of bias in randomised trials, BMJ 343 (2011) d5928.

[8] Royal College of Paediatrics and Child Health, Growth Charts, 2019. https://www.rcpch.ac.uk/resources/growth-charts. (Accessed 11/04/19.

[9] S. Green, J. Higgins, Cochrane handbook for systematic reviews of interventions, Version, 2005. [10] J.A.C. Sterne, A.J. Sutton, J.P.A. Ioannidis, N. Terrin, D.R. Jones, J. Lau, J. Carpenter, G. Rücker, R.M. Harbord, C.H. Schmid, J. Tetzlaff, J.J. Deeks, J. Peters, P. Macaskill, G. Schwarzer, S. Duval, D.G. Altman, D. Moher, J.P.T. Higgins, Recommendations for examining and interpreting funnel plot asymmetry in meta-analyses of randomised controlled trials, BMJ 343 (2011) d4002.

[11] R.G.G. Bhagat, M. M., Effect of corticosteroids on bronchial responsiveness to methacholine in asthmatic children, American Review of Respiratory Disease 131(6) (1985) 902-906.

[12] C.J.S. Bossley, S. Kavanagh, C. Payne, D. N. R. Wilson, N. Tsartsali, L. Rosenthal, M. Balfour-Lynn, I. M. Nicholson, A. G. Bush, A., Corticosteroid responsiveness and clinical characteristics in childhood difficult asthma, European Respiratory Journal 34(5) (2009) 1052-1059.

[13] A.L.A. Fernandes, M. M. Caetano, L. B. Dracoulakis, S. Araruna, A. A. Faresin, S. M. Santoro, I. L., Bronchodilator response as a hallmark of uncontrolled asthma: a randomised clinical trial, J Asthma 51(4) (2014) 405-10.

[14] E.J. Goleva, L. P. Gleason, M. Leung, D. Y., Usefulness of PBMCs to predict clinical response to corticosteroids in asthmatic patients, J Allergy Clin Immunol 129(3) (2012) 687-693.e1.

[15] E.R.L. Sher, D. Y. M. Surs, W. Kam, J. C. Zieg, G. Kamada, A. K. Szefler, S. J., Steroid-resistant asthma - cellular mechanisms contributing to inadequate response to glucocorticoid therapy, J. Clin. Invest. 93(1) (1994) 33-39.

[16] F.L.B. Dente, E. Bartoli, M. L. Cianchetti, S. Costa, F. Di Franco, A. Malagrino, L. Vagaggini, B. Paggiaro, P., Effects of oral prednisone on sputum eosinophils and cytokines in patients with severe refractory asthma, Annals of Allergy, Asthma and Immunology 104(6) (2010) 464-470.

[17] S.A.C. Little, G. W. Thomson, N. C. MacLeod, K. J. McSharry, C., Non-invasive markers of airway inflammation as predictors of oral steroid responsiveness in asthma, Thorax 55(3) (2000) 232-234.

[18] J. Busby, C. Holweg, A. Chai, P. Bradding, F. Cai, R. Chaudhuri, A. Mansur, J. Lordan, J.G. Matthews, A. Menzies-Gow, R.S. Niven, T., L.G. Heaney, Change in type-2 biomarkers and related cytokines with prednisolone treatment in severe oral corticosteroid dependent asthmatics: an interventional openlabel study, (z2.Under Review).

[19] R.L. Chaudhuri, E. McMahon, A. D. Thomson, L. Borland, W. Thomson, N. C., Cigarette Smoking Impairs the Therapeutic Response to Oral Corticosteroids in Chronic Asthma, Am. J. Respir. Crit. Care Med. 168(11) (2003) 1308-1311. 
[20] M.M. Spears, C. Chaudhuri, R. Weir, C. J. de Wet, C. Thomson, N. C., Smoking in Asthma Is Associated with Elevated Levels of Corticosteroid Resistant Sputum Cytokines-An Exploratory Study, PLOS ONE 8 (8) (no pagination)(e71460) (2013).

[21] C.R.W. Jenkins, A. J., Effect of prednisone and beclomethasone dipropionate on airway responsiveness in asthma: a comparative study, Thorax 43(5) (1988) 378-384.

[22] M.C.P. Liu, D. Lichtenstein, L. M. Hubbard, W. C. Bochner, B. S. Stealey, B. A. Breslin, L. Xiao, H. Freidhoff, L. R. Schroeder, J. T. Schleimer, R. P., Effects of prednisone on the cellular responses and release of cytokines and mediators after segmental allergen challenge of asthmatic subjects, Journal of Allergy and Clinical Immunology 108(1) (2001) 29-38.

[23] J.B.P. Wempe, D. S. Breederveld, N. Alting-Hebing, D. Van der Mark, T. W. Koeter, G. H., Separate and combined effects of corticosteroids and bronchodilators on airflow obstruction and airway hyperresponsiveness in asthma, Journal of Allergy and Clinical Immunology 89(3) (1992) 679-687.

[24] D.H.K. Yates, S. A. Robbins, R. A. Thomas, P. S. Barnes, P. J., Effect of a nitric oxide synthase inhibitor and a glucocorticosteroid on exhaled nitric oxide, Am. J. Respir. Crit. Care Med. 152(3) (1995) 892-896.

[25] W.R.W. Beam, D. E. Martin, R. J., Timing of prednisone and alterations of airways inflammation in nocturnal asthma, American Review of Respiratory Disease 146(6) (1992) 1524-1530.

[26] S.E.T. Wenzel, J. B. Westcott, J. Y. Beam, W. R. Martin, R. J., Single oral dose of prednisone decreases leukotriene $B<$ inf $>4</$ inf $>$ production by alveolar macrophages from patients with nocturnal asthma but not control subjects: Relationship to changes in cellular influx and FEV $<$ inf $>1</$ inf $>$, Journal of Allergy and Clinical Immunology 94(5) (1994) 870-881.

[27] N.C. Santanello, J. Zhang, B. Seidenberg, T.F. Reiss, B.L. Barber, What are minimal important changes for asthma measures in a clinical trial?, Eur Respir J 14(1) (1999) 23-7.

[28] B.O. Gemicioglu, B. C. Duman, B., Comparison of allergic asthma patients treated with omalizumab and non-allergic patients treated with continuous oral corticosteroids: results of five year follow-up therapies, Tuberk. Torak 64(2) (2016) 97-104.

[29] R.J. Hancox, I.D. Pavord, M.R. Sears, Associations between blood eosinophils and decline in lung function among adults with and without asthma, European Respiratory Journal 51(4) (2018) 1702536. [30] R.A. Dweik, R.L. Sorkness, S. Wenzel, J. Hammel, D. Curran-Everett, S.A.A. Comhair, E. Bleecker, W. Busse, W.J. Calhoun, M. Castro, K.F. Chung, E. Israel, N. Jarjour, W. Moore, S. Peters, G. Teague, B. Gaston, S.C. Erzurum, S. Natl Heart Lung Blood Inst, Use of Exhaled Nitric Oxide Measurement to Identify a Reactive, at-Risk Phenotype among Patients with Asthma, Am. J. Respir. Crit. Care Med. 181(10) (2010) 1033-1041.

[31] R. Louis, L.C.K. Lau, A.O. Bron, A.C. Roldaan, M. Radermecker, R. Djukanovic, The relationship between airways inflammation and asthma severity, Am. J. Respir. Crit. Care Med. 161(1) (2000) 9-16. [32] H.L. Petsky, C.J. Cates, K.M. Kew, A.B. Chang, Tailoring asthma treatment on eosinophilic markers (exhaled nitric oxide or sputum eosinophils): a systematic review and meta-analysis, Thorax 73(12) (2018) 1110-1119.

[33] D. Robinson, Q. Hamid, S. Ying, A. Bentley, B. Assoufi, S. Durham, A.B. Kay, Prednisolone treatment in asthma is associated with modulation of bronchoalveolar lavage cell interleukin-4, interleukin-5, and interferon-gamma cytokine gene expression, The American review of respiratory disease $148(2)$ (1993) 401-6.

[34] J. Busby, C.T.J. Holweg, A. Chai, P. Bradding, F. Cai, R. Chaudhuri, A.H. Mansur, J.L. Lordan, J.G. Matthews, A. Menzies-Gow, R. Niven, T. Staton, L.G. Heaney, Change in type-2 biomarkers and related cytokines with prednisolone in uncontrolled severe oral corticosteroid dependent asthmatics: an interventional open-label study, Thorax (2019) thoraxjnl-2018-212709.

[35] E.F. Juniper, K. Svensson, A.C. Mork, E. Stahl, Measurement properties and interpretation of three shortened versions of the asthma control questionnaire, Respir Med 99(5) (2005) 553-8.

[36] E.F. Juniper, J. Bousquet, L. Abetz, E.D. Bateman, Identifying 'well-controlled' and 'not wellcontrolled' asthma using the Asthma Control Questionnaire, Respir Med 100(4) (2006) 616-21. 
[37] W. Baigelman, S. Chodosh, D. Pizzuto, L.A. Cupples, Sputum and blood eosinophils during corticosteroid treatment of acute exacerbations of asthma, The American Journal of Medicine 75(6) (1983) 929-936.

[38] R. Semprini, N. Shortt, S. Ebmeier, A. Semprini, R. Varughese, C.T.J. Holweg, J.G. Matthews, J. Fingleton, M. Weatherall, R. Beasley, I. Braithwaite, Change in biomarkers of type-2 inflammation following severe exacerbations of asthma, Thorax 74(1) (2019) 95-98.

[39] M.M. Pizzichini, E. Pizzichini, L. Clelland, A. Efthimiadis, J. Mahony, J. Dolovich, F.E. Hargreave, Sputum in severe exacerbations of asthma: kinetics of inflammatory indices after prednisone treatment, Am J Respir Crit Care Med 155(5) (1997) 1501-8.

[40] K. Al Efraij, K.M. Johnson, D. Wiebe, M. Sadatsafavi, J.M. FitzGerald, A systematic review of the adverse events and economic impact associated with oral corticosteroids in asthma, J Asthma 56(12) (2019) 1334-1346.

[41] T. Volmer, T. Effenberger, C. Trautner, R. Buhl, Consequences of long-term oral corticosteroid therapy and its side-effects in severe asthma in adults: a focused review of the impact data in the literature, European Respiratory Journal 52(4) (2018).

[42] J.A. Arkins, D.P. Schleuter, J.N. Fink, The effect of corticosteroids on methacholine inhalation in symptomatic bronchial asthma, The Journal of allergy 41(4) (1968) 209-16.

[43] R.B. Ellul Micallef, R. C. McHardy, G. J. R., The time course of response to prednisolone in chronic bronchial asthma, Clinical Science and Molecular Medicine 47(2) (1974) 105-117.

[44] I.M.I. Lightbody, C. G. Legge, J. S. Johnston, R. N., Ipratropium bromide, salbutamol and prednisolone in bronchial asthma and chronic bronchitis, British Journal of Diseases of the Chest 72(3) (1978) 181-186.

[45] G.A.P. Settipane, R. K. McGowan, J. H., Corticosteroid effect on immunoglobulins, Journal of Allergy and Clinical Immunology 62(3) (1978) 162-166.

[46] R.F.F. Willey, R. J. Godden, D. J. Crompton, G. K. Grant, I. W., Comparison of oral prednisolone and intramuscular depot triamcinolone in patients with severe chronic asthma, Thorax 39(5) (1984) 340-344.

[47] W.S. Gin, R. J. Kay, A. B., Airways reversibility after prednisolone therapy in chronic asthma is associated with alterations in leukocyte function, American Review of Respiratory Disease 132(6) (1985) 1199-1203.

[48] W.U. Wilmsmeyer, D. Wagner, T. O. F. Sybrecht, G. W., First-time treatment with steroids in bronchial asthma: Comparison of the effects of inhaled beclomethasone and of oral prednisone on airway function, bronchial reactivity and hypothalamic-pituitary-adrenal axis, European Respiratory Journal 3(7) (1990) 786-791.

[49] D.H. Robinson, Q. Ying, S. Bentley, A. Assoufi, B. Durham, S. Kay, A. B., Prednisolone treatment in asthma is associated with modulation of bronchoalveolar lavage cell interleukin-4, interleukin-5, and interferon-gamma cytokine gene expression, American Review of Respiratory Disease 148(2) (1993) 401-406.

[50] H.G.v.U. Bosman, R. Tamminga, J. J. Paanakker, L. R., Comparison of inhaled beclomethasone dipropionate 1000 micrograms twice daily and oral prednisone $10 \mathrm{mg}$ once daily in asthmatic patients, Thorax 49(1) (1994) 37-40.

[51] D.M.B. Claman, H. A. Liu, J. Wong, H. Fahy, J. V., Analysis of induced sputum to examine the effects of prednisone on airway inflammation in asthmatic subjects, Journal of Allergy and Clinical Immunology 94(5) (1994) 861-869.

[52] R.F. Dworski, G. A. Oates, J. A. Sheller, J. R. Workman, R. Prakash, C., Effect of oral prednisone on airway inflammatory mediators in atopic asthma, Am. J. Respir. Crit. Care Med. 149(4) (1994) 953-959. [53] D.S.A. Robinson, B. Durham, S. R. Kay, A. B., Eosinophil cationic protein (ecp) and eosinophil protein-x (epx) concentrations in serum and bronchial lavage fluid in asthma - effect of prednisolone treatment, Clin. Exp. Allergy 25(11) (1995) 1118-1127.

[54] A.M.H. Bentley, Q. Robinson, D. S. Schotman, E. Meng, Q. Assoufi, B. Kay, A. B. Durham, S. R., Prednisolone treatment in asthma - Reduction in the numbers of eosinophils, $T$ cells, tryptase-only 
positive mast cells, and modulation of IL-4, IL-5, and interferon-gamma cytokine gene expression within the bronchial mucosa, Am. J. Respir. Crit. Care Med. 153(2) (1996) 551-556.

[55] R.H. Djukanovic, S. Gratziou, C. Madden, J. Walls, A. Montefort, S. Peroni, D. G. Polosa, R. Holgate, S. Howarth, P., The effect of treatment with oral corticosteroids on asthma symptoms and airway inflammation, Am. J. Respir. Crit. Care Med. 155(3) (1997) 826-832.

[56] V.M.J. Keatings, A. Worsdell, Y. M. Barnes, P. J., Effects of inhaled and oral glucocorticoids on inflammatory indices in asthma and COPD, Am. J. Respir. Crit. Care Med. 155(2) (1997) 542-548.

[57] A.G. Fenech, R. Ellul-Micallef, Selenium, glutathione peroxidase and superoxide dismutase in maltese asthmatic patients: effect of glucocorticoid administration, Pulmonary pharmacology \& therapeutics 11(4) (1998) 301-8.

[58] A.M.M. Wilson, L. C. Lipworth, B. J., Systemic bioactivity profiles of oral prednisolone and nebulized budesonide in adult asthmatics, Chest 114(4) (1998) 1022-1027.

[59] H.S. Matsuse, T. Matsuo, N. Obase, Y. Asai, S. Kohno, S., Corticosteroid resistance in mild asthma: Markers of persistent inflammation, Annals of Allergy, Asthma and Immunology 82(5) (1999) 457-462. [60] R.J.K. Meijer, H. A. M. Arends, L. R. Kauffman, H. F. Koeter, G. H. Postma, D. S., Effects of inhaled fluticasone and oral prednisolone on clinical and inflammatory parameters in patients with asthma, Thorax 54(10) (1999) 894-899.

[61] A.M.L. Wilson, B. J., Short-term dose-response relationships for the relative systemic effects of oral prednisolone and inhaled fluticasone in asthmatic adults, British Journal of Clinical Pharmacology 48(4) (1999) 579-585.

[62] S.K.G. Chhabra, M., Prednisolone hastens recovery from histamine-induced bronchospasm in asthmatics, J Asthma 37(5) (2000) 435-440.

[63] D.C.S. Grootendorst, P. J. Heijerman, H. G. M., Effect of oral prednisolone on the bronchoprotective effect of formoterol in patients with persistent asthma, European Respiratory Journal 17(3) (2001) 374-379.

[64] K.F. Kurashima, M. Myou, S. Kasahara, K. Tachibana, H. Amemiya, N. Ishiura, Y. Onai, N. Matsushima, K. Nakao, S., Effects of oral steroids on blood CXCR3+ and CCR4+ T cells in patients with bronchial asthma, Am. J. Respir. Crit. Care Med. 164(5) (2001) 754-758.

[65] D.N.A. Payne, I. M. Wilson, N. M. Oates, T. Scallan, M. Bush, A., Relationship between exhaled nitric oxide and mucosal eosinophilic inflammation in children with difficult asthma, after treatment with oral prednisolone, Am J Respir Crit Care Med 164(8 Pt 1) (2001) 1376-81.

[66] J.H. Chakir, Q. Bosse, M. Boulet, L. P. Laviolette, M., Bronchial inflammation in corticosteroidsensitive and corticosteroid-resistant asthma at baseline and on oral corticosteroid treatment, Clin. Exp. Allergy 32(4) (2002) 578-582.

[67] A.F.T. Gelb, C. F. Nussbaum, E. Gutierrez, C. Schein, A. Shinar, C. M. Schein, M. J. Epstein, J. D. Zamel, N., Alveolar and airway sites of nitric oxide inflammation in treated asthma, Am. J. Respir. Crit. Care Med. 170(7) (2004) 737-741.

[68] M.H. Berry, B. Morgan, A. Shelley, M. Richter, J. Shaw, D. Green, R. H. Brightling, C. Wardlaw, A. J. Pavord, I. D., Alveolar nitric oxide in adults with asthma: Evidence of distal lung inflammation in refractory asthma, European Respiratory Journal 25(6) (2005) 986-991.

[69] M.B. Fukakusa, C. Tulic, M. K. Fiset, P. O. Al Dewachi, O. Laviolette, M. Hamid, Q. Chakir, J., Oral corticosteroids decrease eosinophil and CC chemokine expression but increase neutrophil, IL-8, and IFN-gamma-inducible protein 10 expression in asthmatic airway mucosa, Journal of Allergy and Clinical Immunology 115(2) (2005) 280-286.

[70] C.P. Lex, D. N. R. Zacharasiewicz, A. Li, A. M. Nicholson, A. G. Wilson, N. M. Bush, A., Is a two-week trial of oral prednisolone predictive of target lung function in pediatric asthma?, Pediatric Pulmonology 39(6) (2005) 521-527.

[71] L.T.L. Nguyen, S. Oates, T. Chung, K. F., Increase in airway neutrophils after oral but not inhaled corticosteroid therapy in mild asthma, Respiratory Medicine 99(2) (2005) 200-207. 
[72] A.M.S. Slats, J. K. Van Klink, R. H. C. J. Bel, E. H. D. Sterk, P. J., Improvement in bronchodilation following deep inspiration after a course of high-dose oral prednisone in asthma, Chest 130(1) (2006) 58-65.

[73] B.C. Vagaggini, S. Bartoli, M. Ricci, M. Bacci, E. Dente, F. L. Di Franco, A. Paggiaro, P., Prednisone blunts airway neutrophilic inflammatory response due to ozone exposure in asthmatic subjects, Respiration 74(1) (2007) 61-68.

[74] E.R.G. Sutherland, E. Strand, M. Beuther, D. A. Leung, D. Y. M., Body mass and glucocorticoid response in asthma, Am. J. Respir. Crit. Care Med. 178(7) (2008) 682-687.

[75] A.D.C. Smith, J. O. Taylor, D. R., Exhaled nitric oxide levels in asthma: Personal best versus reference values, Journal of Allergy and Clinical Immunology 124(4) (2009) 714-718.e4.

[76] M.W. Spears, C. J. Smith, A. D. McSharry, C. Chaudhuri, R. Johnson, M. Cameron, E. Thomson, N. C., Bronchial nitric oxide flux (J'aw) is sensitive to oral corticosteroids in smokers with asthma, Respiratory Medicine 105(12) (2011) 1823-1830.

[77] E.J. Goleva, L. P. Harris, J. K. Robertson, C. E. Sutherland, E. R. Hall, C. F. Good Jr, J. T. Gelfand, E. W. Martin, R. J. Leung, D. Y. M., The effects of airway microbiome on corticosteroid responsiveness in asthma, Am. J. Respir. Crit. Care Med. 188(10) (2013) 1193-1201.

[78] K.H. Matsunaga, T. Akamatsu, K. Minakata, Y., Predictors for identifying the efficacy of systemic steroids on sustained exhaled nitric oxide elevation in severe asthma, Allergology International 62(3) (2013) 359-365.

[79] M.P.P. Van der Schee, R. Cowan, J. O. Taylor, D. R., Predicting steroid responsiveness in patients with asthma using exhaled breath profiling, Clin. Exp. Allergy 43(11) (2013) 1217-1225.

[80] P.A.S. Williamson, P. M. Vaidyanathan, S. Lipworth, B. J., Inhaled and systemic corticosteroid response in severe asthma assessed by alveolar nitric oxide: A randomized crossover pilot study of add-on therapy, British Journal of Clinical Pharmacology 75(1) (2013) 93-102.

[81] C.Y. Yick, A.H. Zwinderman, P.W. Kunst, K. Grunberg, T. Mauad, K. Fluiter, E.H. Bel, R. Lutter, F. Baas, P.J. Sterk, Glucocorticoid-induced changes in gene expression of airway smooth muscle in patients with asthma, Am J Respir Crit Care Med 187(10) (2013) 1076-84.

[82] B.S.G. Berthon, P. G. Wood, L. G. MacDonald-Wicks, L. K. Baines, K. J., A sputum gene expression signature predicts oral corticosteroid response in asthma, The European respiratory journal $49(6)$ (2017). 


\section{Tables and Figures}

Table 1: Description of included studies

\begin{tabular}{|c|c|c|c|c|c|c|c|c|c|c|c|c|}
\hline Study ID & Country & Design $^{\text {b }}$ & Stability $^{c}$ & Patients & Mean Age & Male (\%) & FEV $_{1}(\%)$ & ICS \% & OCS \% & Medication $^{d}$ & Dose & Time $^{\mathrm{e}}$ \\
\hline Arkins (1968)[42] & USA & OBA & $\mathrm{U}$ & 11 & 49.1 & 36.4 & 47.7 & NS & NS & Pred & $30 \mathrm{mg}$ & $2 W$ \\
\hline Ellul Micallef (1974)[43] & UK & OBA & U & 6 & 55.7 & 33.3 & 33.2 & 0 & 0 & Pred & $40 \mathrm{mg}$ & $1 \mathrm{D}$ \\
\hline Lightbody (1978)[44] & UK & OBA & NS & 11 & 36.5 & NS & 51.6 & NS & NS & Pred & $30 \mathrm{mg}$ & $3 D$ \\
\hline Settipane (1978)[45] & USA & OBA & $\mathrm{U}$ & 9 & 14.0 & 44.4 & NS & 0 & 0 & Pred & Mean: $16.8 \mathrm{mg}$ & $15 \mathrm{D}$ \\
\hline Willey (1984)[46] & UK & CRCT & $\mathrm{C}$ & 20 & 48.9 & 40.0 & 38.4 & 100 & 100 & Pred & $10 \mathrm{mg}$ & $2 W, 4 W$ \\
\hline Bhagat (1985)[11] & USA & OBA & $\mathrm{C}$ & 10 & 12.1 & 60.0 & 84.0 & 0 & 0 & Pred & $60 \mathrm{mg}$ & $1 \mathrm{~W}$ \\
\hline Gin (1985)[47] & UK & OBA & NS & 6 & 47.5 & 66.7 & NS & 67 & 0 & Pred & $30 \mathrm{mg}$ & $1 \mathrm{~W}$ \\
\hline Jenkins (1988)[21] & Australia & CRCT & $\mathrm{C}$ & 18 & 42.0 & 50.0 & 56.1 & 100 & 22 & Pred & $12.5 \mathrm{mg}$ & $21 D$ \\
\hline Wilmsmeyer (1990)[48] & Germany & OBA & NS & 12 & 29.9 & 66.7 & 73.3 & 0 & 0 & Pred & $15 \mathrm{mg}$ & $14 \mathrm{D}$ \\
\hline Beam (1992)[25] & USA & CRCT & $\mathrm{C}$ & 7 & 32.6 & 100.0 & 84.3 & 0 & 0 & Pred & $50 \mathrm{mg}$ & $1 \mathrm{D}$ \\
\hline Wempe (1992)[23] & Netherlands & CRCT & C & 12 & 28.8 & 75.0 & 67.7 & 75 & 0 & Pred & $40 \mathrm{mg}$ & $8 \mathrm{D}$ \\
\hline Robinson (1993)[49] & UK & PRCT & U & 18 & 24.8 & 33.3 & 80.1 & 0 & 0 & Pred & $0.6 \mathrm{mg} / \mathrm{kg}$ & $2 W$ \\
\hline Bosman (1994)[50] & Netherlands & CRCT & NS & 17 & 39.1 & 70.6 & 86.0 & 100 & 0 & Pred & $10 \mathrm{mg}$ & $4 W$ \\
\hline Claman (1994)[51] & USA & PRCT & NS & 24 & 29.8 & 54.2 & 81.3 & 0 & 0 & Pred & $0.5 \mathrm{mg} / \mathrm{kg}$ & $6 \mathrm{D}$ \\
\hline Dworski (1994)[52] & USA & OBA & NS & 20 & NS & 45.0 & 92.3 & 0 & 0 & Pred & $>20 \mathrm{mg}$ & $7-9 D$ \\
\hline Sher (1994)[15] & USA & OBA & NS & 29 & 24.0 & 69.0 & 53.4 & 69 & 41 & Pred & $40 \mathrm{mg}$ & $7 D$ \\
\hline Wenzel (1994)[26] & USA & CRCT & NS & 14 & 32.5 & 64.2 & 89.0 & 0 & 0 & Pred & $50 \mathrm{mg}$ & $1 \mathrm{D}$ \\
\hline Chhabra (1995)[4] & India & OBA & $\mathrm{C}$ & 10 & 23.1 & 60.0 & 41.0 & 100 & 0 & Pred & $30 \mathrm{mg}$ & $1 \mathrm{~W}$ \\
\hline Robinson (1995)[53] & UK & PRCT & $U$ & 18 & 23.3 & 33.3 & 81.6 & 0 & 0 & Pred & $0.6 \mathrm{mg} / \mathrm{kg}$ & $14 \mathrm{D}$ \\
\hline Yates (1995)[24] & UK & CRCT & $\mathrm{C}$ & 6 & 27.2 & 83.3 & 97.0 & NS & NS & Pred & $30 \mathrm{mg}$ & $3 D$ \\
\hline Bentley (1996)[54] & UK & PRCT & $\mathrm{U}$ & 18 & 24.8 & 38.9 & 81.0 & 0 & 0 & Pred & $0.6 \mathrm{mg} / \mathrm{kg}$ & $14 \mathrm{D}$ \\
\hline Djukanovic (1997)[55] & UK & PRCT & $U$ & 27 & 24.0 & NS & 88.8 & 0 & 0 & Pred & $10 \mathrm{mg}, 20 \mathrm{mg}$ & $6 \mathrm{~W}$ \\
\hline Keatings (1997)[56] & UK & OBA & $\mathrm{C}$ & 10 & NS & NS & 100.4 & 0 & 0 & Pred & $30 \mathrm{mg}$ & $2 \mathrm{~W}$ \\
\hline Fenech (1998)[57] & Malta & OBA & $\mathrm{C}$ & 16 & NS & NS & 61.1 & 0 & 0 & Pred & $5 \mathrm{mg}, 10 \mathrm{mg}, 15 \mathrm{mg}$ & $3 W$ \\
\hline Wilson (1998)[58] & UK & CRCT & $\mathrm{C}$ & 12 & 34.7 & 50.0 & 86.8 & 100 & 0 & Pred & $5 \mathrm{mg}, 10 \mathrm{mg}, 20 \mathrm{mg}$ & $12 \mathrm{D}$ \\
\hline Matsuse (1999)[59] & Japan & OBA & C & 11 & 40.2 & 18.2 & 80.5 & 0 & 0 & Pred & $30 \mathrm{mg}$ & $14 \mathrm{D}$ \\
\hline Meijer (1999)[60] & Netherlands & PRCT & NS & 40 & 28.0 & 35.0 & 80.0 & 68 & 0 & Pred & $30 \mathrm{mg}$ & $14 \mathrm{D}$ \\
\hline Wilson (1999)[61] & UK & CRCT & $\mathrm{C}$ & 12 & 28.8 & 50.0 & 94.7 & 100 & 0 & Pred & $5 \mathrm{mg}, 10 \mathrm{mg}, 20 \mathrm{mg}$ & $12 \mathrm{D}$ \\
\hline Chhabra (2000)[62] & India & OBA & $\mathrm{C}$ & 10 & 25.4 & 60.0 & 74.8 & 100 & 0 & Pred & $0.6-0.75 \mathrm{mg} / \mathrm{kg}$ & $1 \mathrm{~W}$ \\
\hline Little (2000)[17] & UK & OBA & $\mathrm{C}$ & 37 & 48.6 & 48.6 & 76.3 & 97 & NS & Pred & $30 \mathrm{mg}$ & $14 D$ \\
\hline Grootendorst (2001)[63] & Netherlands & PRCT & $\mathrm{C}$ & 22 & 39.4 & 31.8 & 89.6 & 100 & 0 & Pred & $30 \mathrm{mg}$ & $7 D$ \\
\hline Kurashima (2001)[64] & Japan & PRCT & C & 28 & 41.2 & 53.6 & 84.3 & 68 & 0 & Pred & $20 \mathrm{mg}$ & $14 \mathrm{D}$ \\
\hline
\end{tabular}




\begin{tabular}{|c|c|c|c|c|c|c|c|c|c|c|c|c|}
\hline Liu (2001)[22] & USA & CRCT & NS & 10 & NS & 60.0 & 79.2 & 0 & 0 & Pred & $60 \mathrm{mg}$ & $3 D$ \\
\hline Payne (2001)[65] & UK & OBA & $U$ & 31 & 11.9 & 61.3 & 69.8 & 100 & 32 & Pred & $40 \mathrm{mg}$ & $14 \mathrm{D}$ \\
\hline Chakir (2002)[66] & Canada & OBA & $U$ & 21 & 36.6 & 42.9 & 59.8 & 91 & 0 & Mpred & $40 \mathrm{mg}$ & $14 \mathrm{D}$ \\
\hline Chaudhuri (2003)[19] & UK & CRCT & $\mathrm{C}$ & 50 & 42.3 & 72.0 & 69.4 & 100 & 0 & Pred & $40 \mathrm{mg}$ & 14D \\
\hline Gelb (2004)[67] & USA & OBA & $\mathrm{C}$ & 10 & 59.0 & 40.0 & 62.0 & 100 & 0 & Pred & $30 \mathrm{mg}$ & $5 \mathrm{D}$ \\
\hline Berry (2005)[68] & UK & OBA & $U$ & 11 & 44.0 & 51.9 & 64.0 & 100 & 22 & Pred & $30 \mathrm{mg}$ & 14D \\
\hline Fukakusa (2005)[69] & Canada & OBA & NS & 13 & 31.0 & 61.5 & 58.0 & NS & 0 & Mpred & $40 \mathrm{mg}$ & $14 \mathrm{D}$ \\
\hline Lex (2005)[70] & UK & OBA & $U$ & 22 & 11.6 & 63.6 & 70.0 & 100 & 14 & Pred & $40 \mathrm{mg}$ & 14D \\
\hline Nguyen (2005)[71] & UK & PRCT & $\mathrm{C}$ & 17 & 23.6 & NS & 80.2 & 0 & 0 & Pred & $30 \mathrm{mg}$ & 7D \\
\hline Slats (2006)[72] & Netherlands & PRCT & $\mathrm{C}$ & 24 & 29.6 & 37.5 & 87.9 & 100 & 0 & Pred & $0.5 \mathrm{mg} / \mathrm{kg}$ & $14 \mathrm{D}$ \\
\hline Vagaggini (2007)[73] & Italy & CRCT & $\mathrm{C}$ & 9 & 25.0 & 88.9 & 88.3 & 0 & 0 & Pred & $25 \mathrm{mg}$ & $4 \mathrm{D}$ \\
\hline Sutherland (2008)[74] & USA & OBA & NS & 33 & 40.0 & 51.5 & 70.7 & 100 & 0 & Pred & $40 \mathrm{mg}$ & $7 D$ \\
\hline Bossley (2009)[12] & UK & OBA & $U$ & 61 & 11.8 & 59.0 & 57.0 & 100 & 36 & Pred & $40 \mathrm{mg}$ & 14D \\
\hline Smith (2009)[75] & New Zealand & OBA & $\mathrm{C}$ & 73 & 44.0 & 43.8 & 82.8 & 100 & 0 & Pred & $30 \mathrm{mg}$ & 14D \\
\hline Dente (2010)[16] & Italy & PRCT & $\mathrm{C}$ & 59 & 58.2 & 37.3 & 68.9 & 100 & 31 & Pred & $0.5 \mathrm{mg} / \mathrm{kg}$ & $14 \mathrm{D}$ \\
\hline Spears (2011)[76] & UK & OBA & $\mathrm{C}$ & 43 & 44.6 & 46.5 & 73.5 & 100 & 0 & Dmeth & $6 \mathrm{mg} / 1.74 \mathrm{~m}^{2}$ & 14D \\
\hline Goleva (2012)[14] & USA & OBA & $U$ & 19 & 32.4 & 26.3 & 66.5 & 68 & 0 & Pred & $40 \mathrm{mg}$ & 7D \\
\hline Goleva (2013)[77] & USA & OBA & NS & 39 & 35.1 & 41.0 & 72.6 & 41 & 0 & Pred & $40 \mathrm{mg}$ & $7 D$ \\
\hline Kupczyk (2013)[5] & Europe-wide & PRCT & NS & 151 & 47.2 & 58.2 & 80.5 & 100 & 0 & Pred & $0.5 \mathrm{mg} / \mathrm{kg}$ & $2 W$ \\
\hline Matsunaga (2013)[78] & Japan & OBA & NS & 20 & 53.5 & 50.0 & 66.2 & 100 & 0 & Pred & $0.5 \mathrm{mg} / \mathrm{kg}$ & $14 \mathrm{D}$ \\
\hline Spears (2013)[20] & UK & OBA & $\mathrm{C}$ & 53 & 45.6 & 47.2 & 74.6 & 100 & 0 & Dmeth & $6 \mathrm{mg} / 1.74 \mathrm{~m}^{2}$ & 14D \\
\hline Van der Schee (2013)[79] & New Zealand & OBA & $\mathrm{C}$ & 25 & 46.0 & 44.0 & 79.8 & 88 & 0 & Pred & $30 \mathrm{mg}$ & $14 \mathrm{D}$ \\
\hline Williamson (2013)[80] & UK & OBA & NS & 15 & 51.0 & 80.0 & 63.4 & 100 & 0 & Pred & $25 \mathrm{mg}$ & $7 D$ \\
\hline Yick (2013)[81] & Netherlands & PRCT & $\mathrm{C}$ & 12 & 25.0 & NS & NS & 0 & 0 & Pred & $0.5 \mathrm{mg} / \mathrm{kg}$ & $2 W$ \\
\hline Fernandes (2014)[13] & Brazil & PRCT & $\mathrm{C}$ & 70 & 46.5 & 27.0 & 70.9 & 100 & 0 & Pred & $40 \mathrm{mg}$ & $2 W$ \\
\hline Gemicioglu (2016)[28] & Turkey & OBA & $U$ & 16 & 52.3 & 6.3 & 61.3 & 100 & 0 & Mpred & Median: 8mg & $5 Y$ \\
\hline Berthon (2017)[82] & Australia & CRCT & $\mathrm{C}$ & 54 & 53.6 & 41.8 & 82.0 & 67 & 0 & Pred & $50 \mathrm{mg}$ & $10 \mathrm{D}$ \\
\hline Sousa (2017)[6] & USA\&UK & OBA & $\mathrm{C}$ & 82 & 36.5 & 41.5 & 78.8 & 65 & 15 & Pred & $0.5 \mathrm{mg} / \mathrm{kg}$ & $14 D$ \\
\hline Busby (2019)[18] & UK & OBA & U & 44 & 52.9 & 45.0 & 62.4 & 100 & 100 & Pred & $0.5 \mathrm{mg} / \mathrm{kg}$ & 7D \\
\hline
\end{tabular}

${ }^{\text {a }}$ NS: Not specified

${ }^{\mathrm{b}}$ OBA: Observational before and after; OP: Observational parallel; CRCT: Crossover randomised controlled trail; PRCT: Parallel randomised controlled trial 'U: Uncontrolled; C: Controlled

dPred: Prednisolone; Dmeth: Dexamethasone; Mpred: Methylprednisolone

${ }^{\mathrm{e}} \mathrm{D}$ : Day; W: Week; Y: Year 
Figure 1: Study Flow Diagram
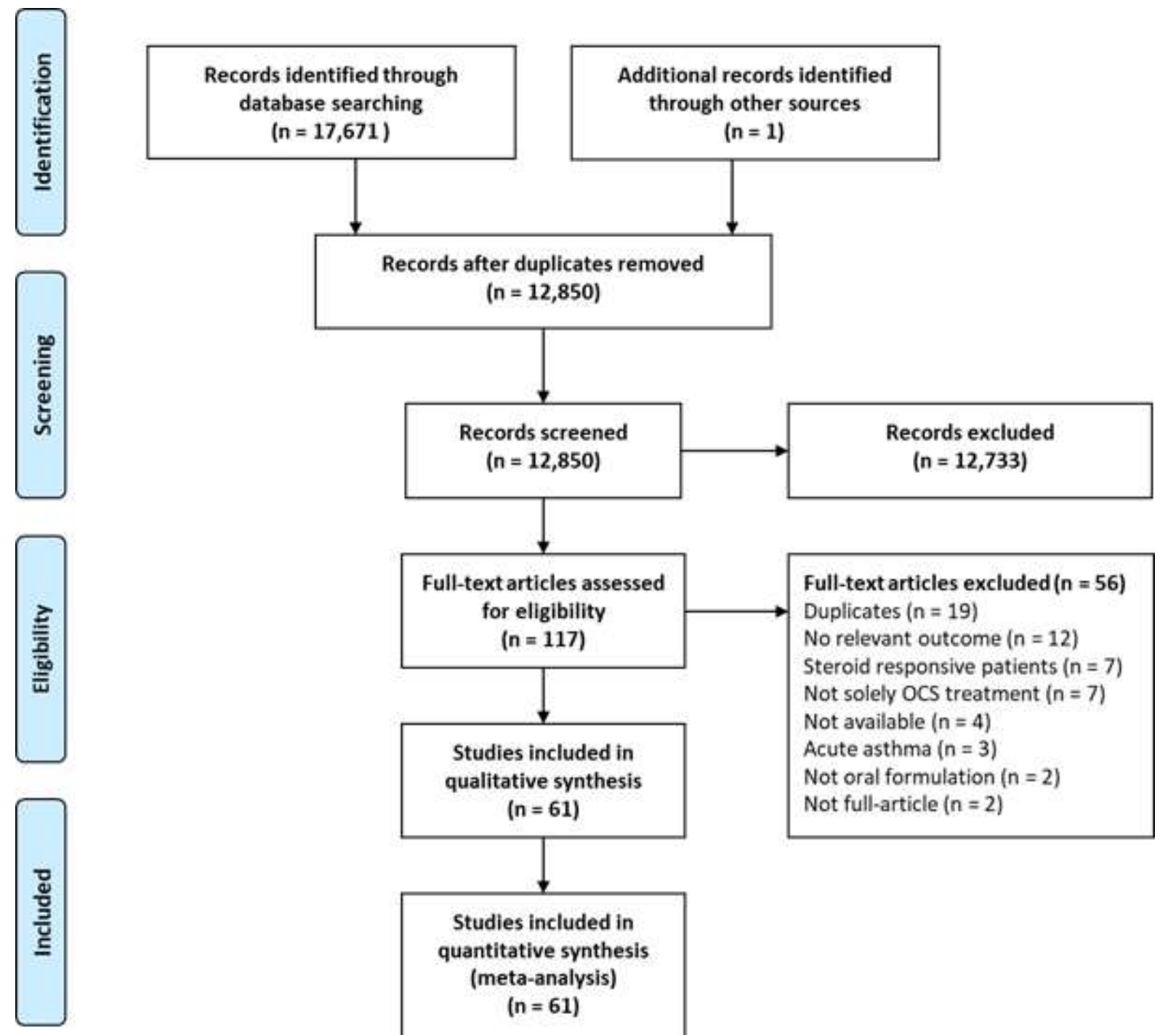

Studies included in

quantitative synthesis

(meta-analysis)

( $\mathrm{n}=61$ ) 
Table 2: Weighted percentage change in all study outcomes following OCS

\begin{tabular}{lcccc}
\hline Outcome & Studies & Patients & \% Change (95\% Cl) & $\mathbf{I}^{\mathbf{2}}$ \\
\hline FEV $_{1}$ & 52 & 1,216 & $9(7,11)$ & $74.6 \%$ \\
FVC & 19 & 371 & $5(3,7)$ & $71.1 \%$ \\
Blood Eosinophils & 10 & 227 & $-76(-88,-63)$ & $34.1 \%$ \\
Sputum Eosinophils & 10 & 277 & $-89(-98,-79)$ & $15.1 \%$ \\
FeNO & 11 & 381 & $-35(-41,-28)$ & $0.0 \%$ \\
ACQ & 9 & 247 & $-20(-29,-11)$ & $33.4 \%$ \\
AQLQ & 2 & 45 & $6(2,9)$ & $0.0 \%$ \\
\hline
\end{tabular}


Figure 2: Weighted percentage change in FEV1 following OCS. Squares indicate study-specific risk estimates (size of the square reflects the study-specific weight); horizontal lines indicate $95 \%$ confidence intervals (Cls); diamond indicates summary estimate with its corresponding 95\% confidence interval.

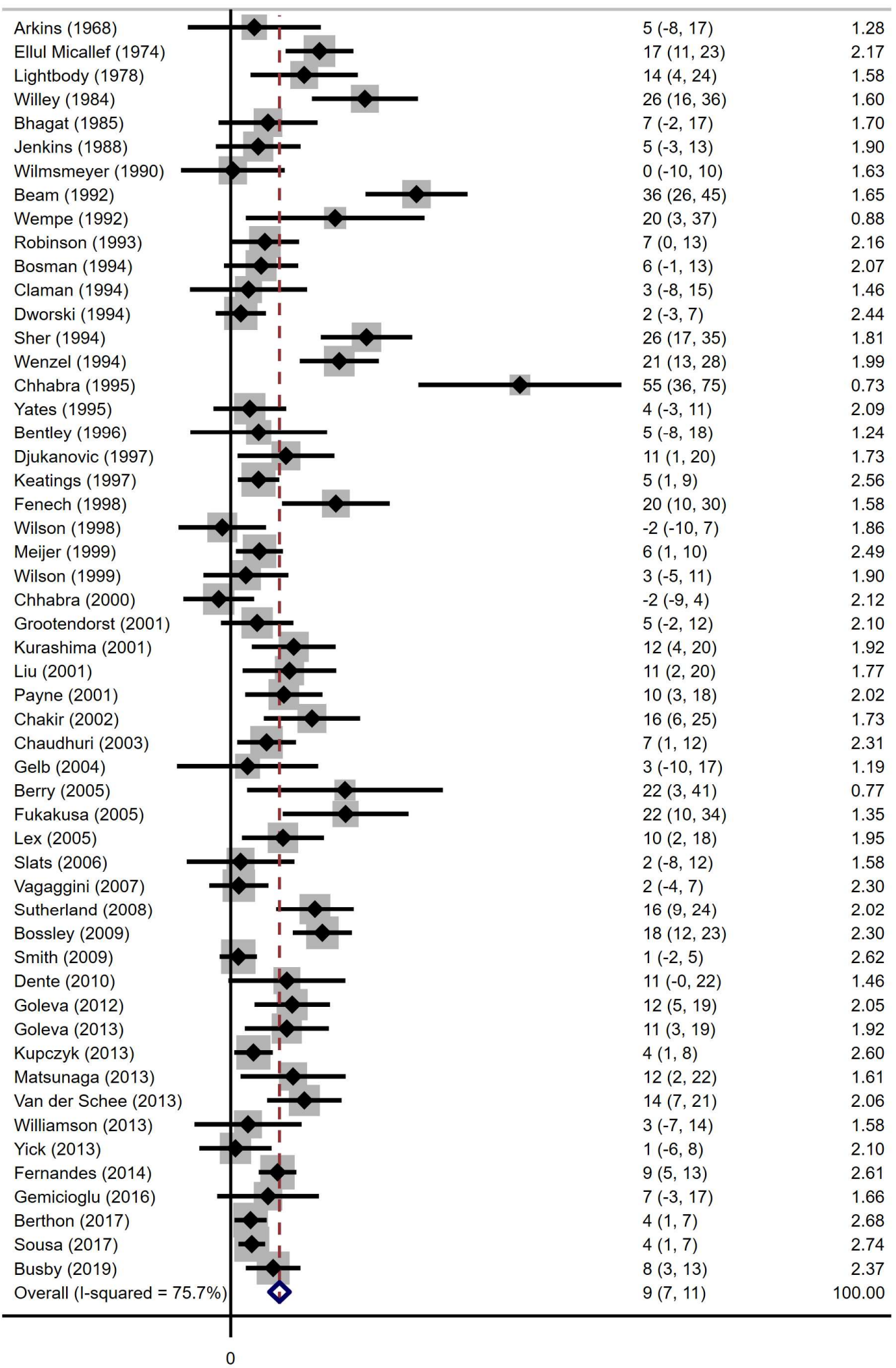


Figure 3: Weighted percentage change in type-2 biomarkers following OCS. Squares indicate studyspecific risk estimates (size of the square reflects the study-specific weight); horizontal lines indicate 95\% confidence intervals (Cls); diamond indicates summary estimate with its corresponding $95 \%$ confidence interval.

\section{Blood Eosinophils}

Study Name

Gin (1985)

Beam (1992)

Wilson (1998)

Matsuse (1999)

Wilson (1999)

Liu (2001)

Matsunaga (2013)

Berthon (2017)

Sousa (2017)

Busby (2019)

Overall (I-squared $=34.1 \%)$

\section{Sputum Eosinophils}

Study Name

Claman (1994)

Keatings (1997)

Meijer (1999)

Little (2000)

Berry (2005)

Nguyen (2005)

Dente (2010)

Spears (2013)

Berthon (2017)

Sousa (2017)

Overall $(\mathrm{I}$-squared $=15.1 \%)$

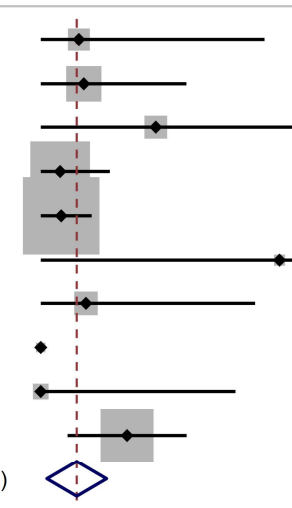

$\%$ Change (95\% CI)

$\%$ Weight

$-88(-100,-29)$

$-86(-100,-54)$

7.52

$-64(-100,-8)$

2.76

$-94(-100,-78)$

23.70

$-94(-100,-84)$

40.36

$-25(-100,122)$

$-86(-100,-32)$

$-100(-100,-99)$

$-100(-100,-38)$

$-73(-92,-54)$

$-89(-98,-79)$

0.41

2.97

0.26

1.09

18.45

100.00

\section{FeNO}

\begin{tabular}{|c|c|c|}
\hline Study Name & $\%$ Change $(95 \% \mathrm{Cl})$ & $\%$ Weight \\
\hline Berry (2005) & $-44(-96,7)$ & 1.49 \\
\hline Slats (2006) & $-44(-100,16)$ & 1.08 \\
\hline Bossley (2009) & $-37(-66,-8)$ & 4.65 \\
\hline Smith (2009) & $-14(-38,11)$ & 6.47 \\
\hline Spears (2011) & $-48(-85,-12)$ & 2.89 \\
\hline Matsunaga (2013) & $-37(-68,-6)$ & 4.06 \\
\hline Van der Schee (2013) & $-44(-63,-25)$ & 10.96 \\
\hline Williamson (2013) & $-36(-66,-7)$ & 4.58 \\
\hline Berthon (2017) & $-28(-57,2)$ & 4.48 \\
\hline Sousa (2017) & $-34(-42,-25)$ & 50.48 \\
\hline Busby (2019) & $-36(-57,-15)$ & 8.85 \\
\hline Overall $(\mathrm{I}$-squared $=0.0 \%)$ & $-35(-41,-28)$ & 100.00 \\
\hline
\end{tabular}


Figure 4: Weighted percentage change in ACQ following OCS. Squares indicate study-specific risk estimates (size of the square reflects the study-specific weight); horizontal lines indicate $95 \%$ confidence intervals (Cls); diamond indicates summary estimate with its corresponding 95\% confidence interval.

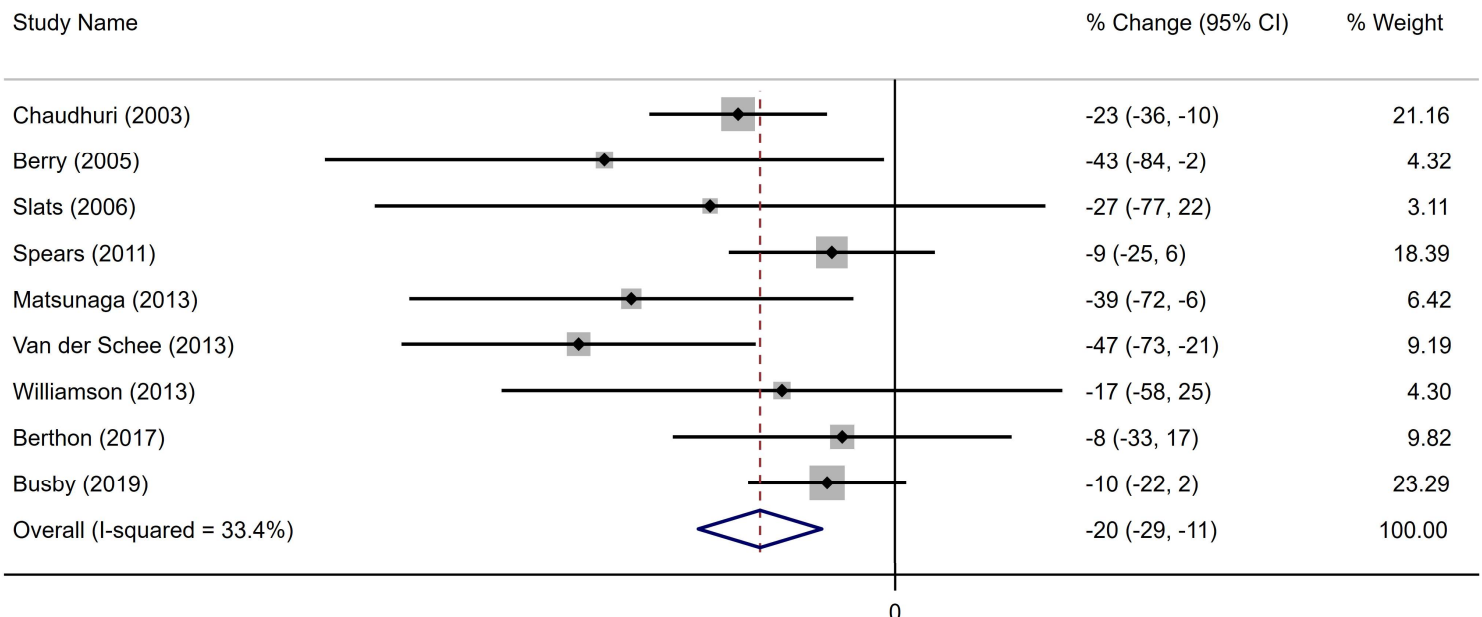




\section{Appendices}

Appendix 1: Electronic search terms

\section{Web of science}

TS=(prednisolone OR prednisalone OR prednisone OR ((oral OR systemic) NEAR/2 (corticosteroid* OR steroid* OR glucocorticoid*))) AND TS=asthma

\section{Medline: Ovid MEDLINE(R) 1946 to October Week 52018}

(prednisolone OR prednisalone OR prednisone OR ((oral OR systemic) ADJ2 (corticosteroid* OR steroid* OR glucocorticoid*))).mp AND asthma

\section{Embase: Embase 1974 to 2018 November 07}

(prednisolone OR prednisalone OR prednisone OR ((oral OR systemic) ADJ2 (corticosteroid* OR steroid* OR glucocorticoid*))).mp AND asthma AND (article or review).pt 


\section{Appendix 2: Weighted percentage change in $\mathrm{FEV}_{1}$ following OCS, stratified by baseline $\mathrm{FEV}_{1}{ }^{\mathrm{a}}$}

Baseline FEV1 and Study Name

\% Change $(95 \% \mathrm{Cl}) \%$ Weight

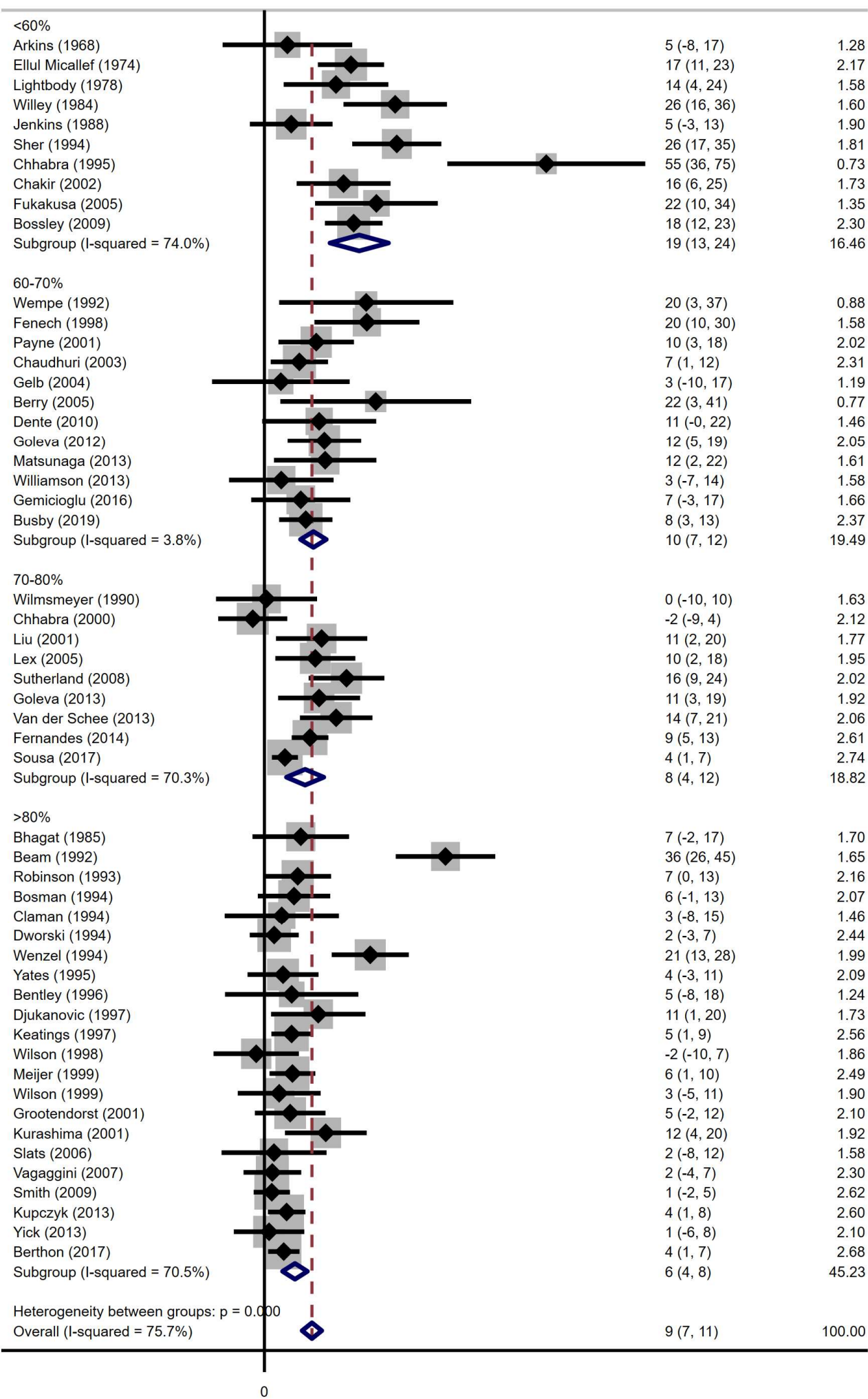

${ }^{\text {a }}$ Squares indicate study-specific risk estimates (size of the square reflects the study-specific weight); horizontal lines indicate $95 \%$ confidence intervals (Cls); diamond indicates summary estimate with its corresponding $95 \%$ confidence interval. 
Appendix 3: Weighted percentage change in $\mathrm{FEV}_{1}$ following OCS, stratified by stability

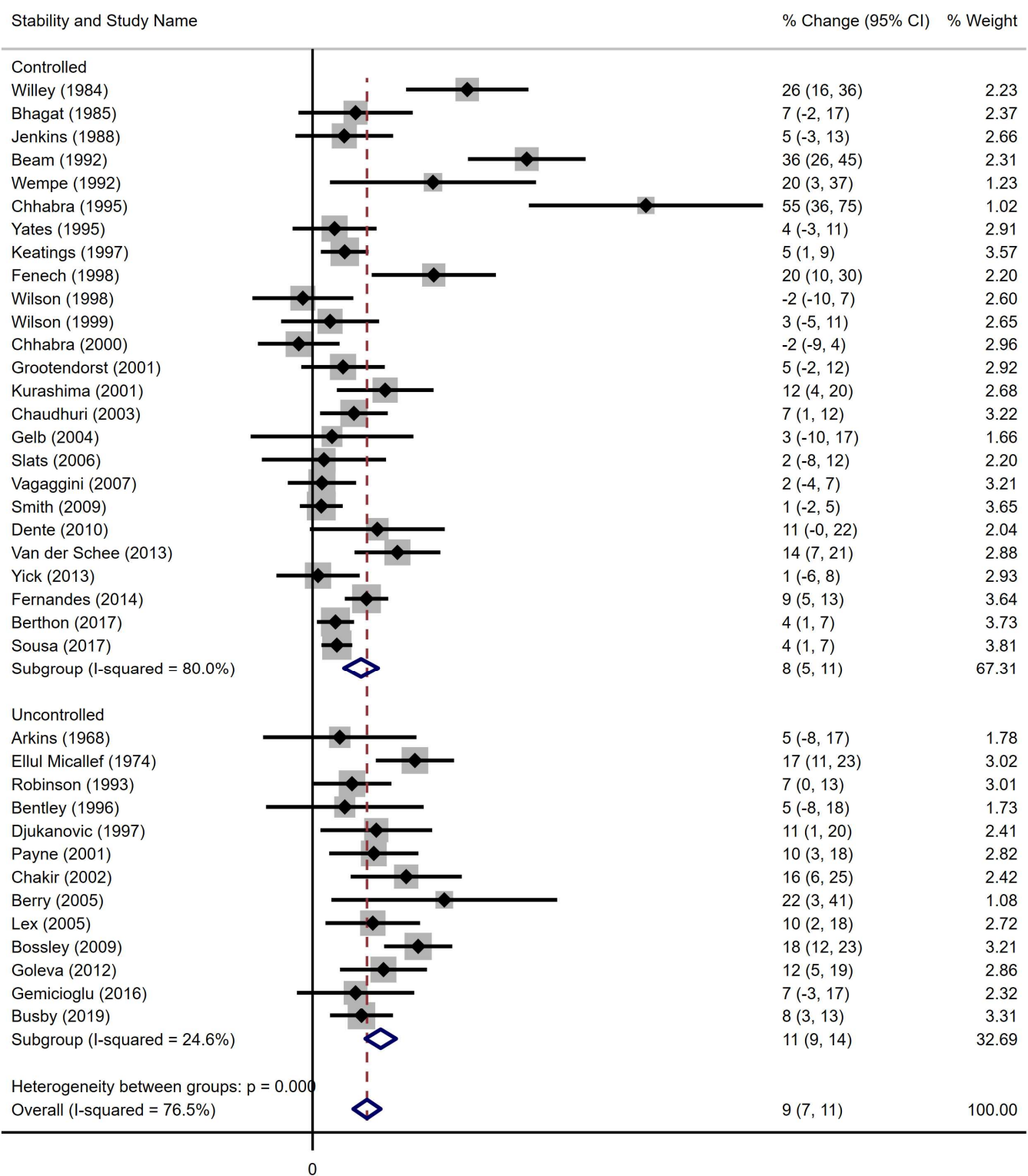

${ }^{a}$ Squares indicate study-specific risk estimates (size of the square reflects the study-specific weight); horizontal lines indicate $95 \%$ confidence intervals $(\mathrm{Cls})$; diamond indicates summary estimate with its corresponding $95 \%$ confidence interval. 
Appendix 4: Weighted percentage change in FVC following OCS ${ }^{a}$

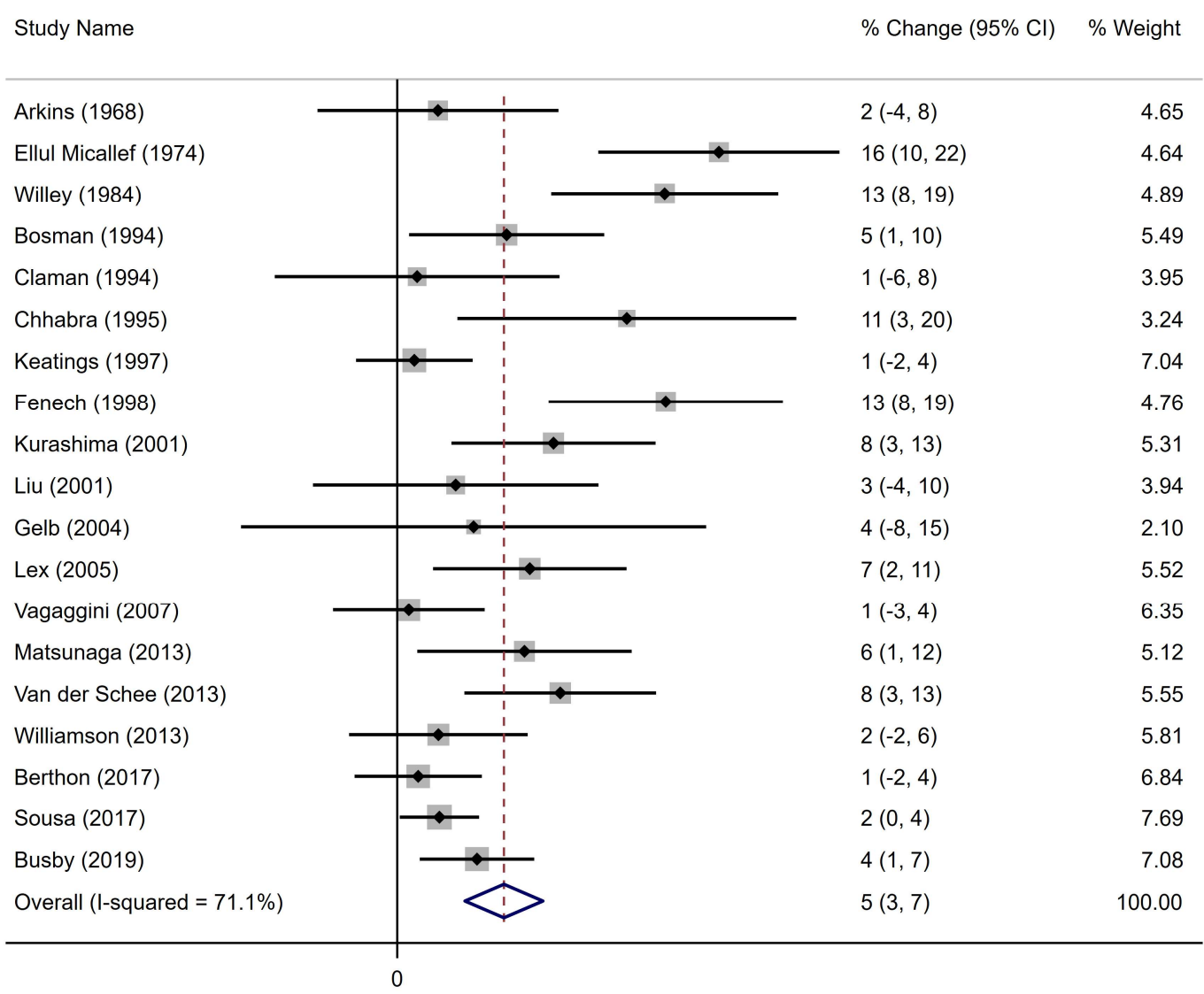

${ }^{\text {a }}$ Squares indicate study-specific risk estimates (size of the square reflects the study-specific weight); horizontal lines indicate $95 \%$ confidence intervals (Cls); diamond indicates summary estimate with its corresponding $95 \%$ confidence interval. 
Appendix 5: Weighted percentage change in blood eosinophils following OCS, stratified by maintenance corticosteroid use $\mathrm{a}^{\mathrm{a}}$

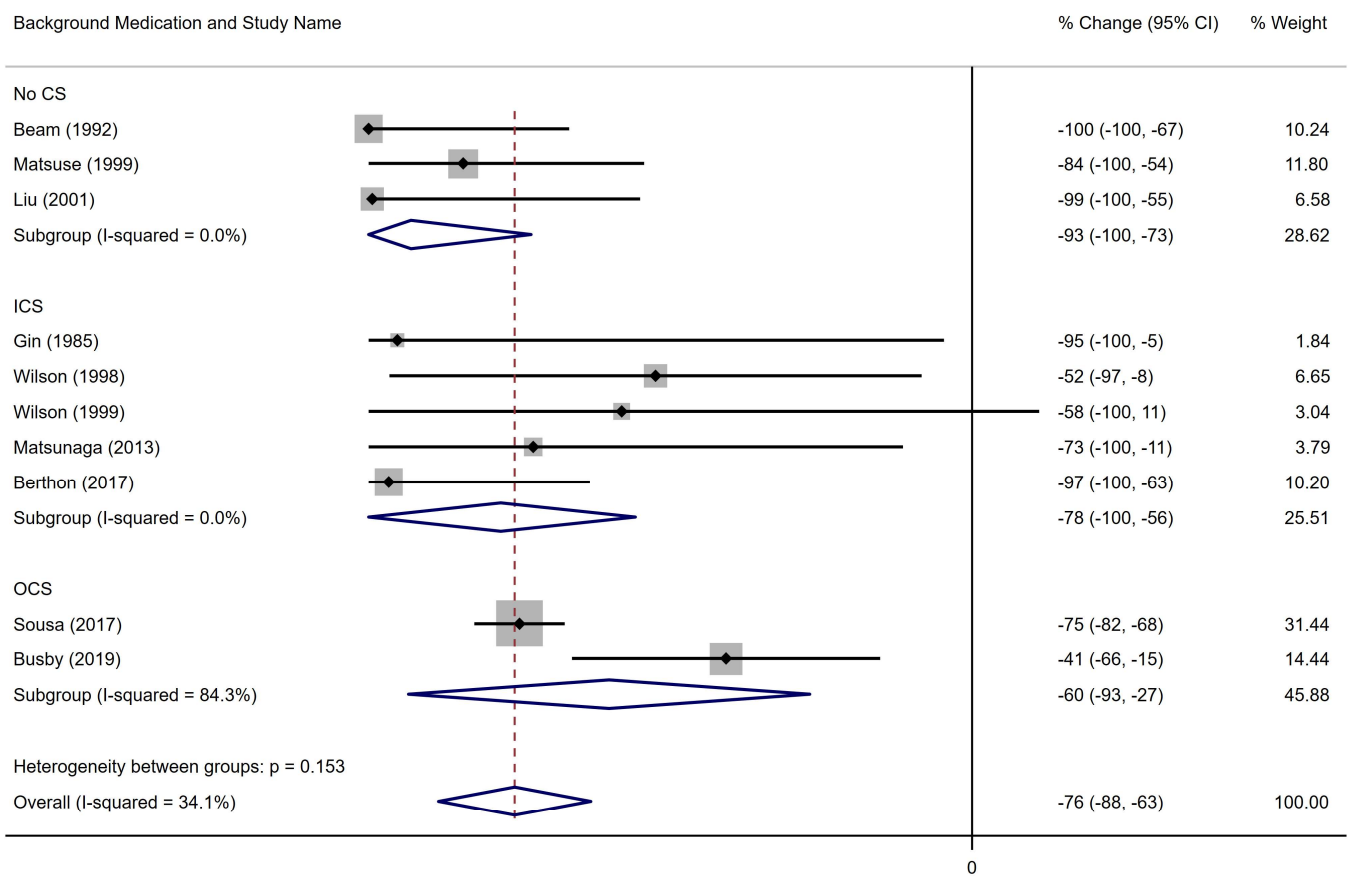

${ }^{a}$ Squares indicate study-specific risk estimates (size of the square reflects the study-specific weight); horizontal lines indicate $95 \%$ confidence intervals (Cls); diamond indicates summary estimate with its corresponding $95 \%$ confidence interval. 
Appendix 6: Weighted percentage change in AQLQ following OCS

\begin{tabular}{|c|c|c|c|}
\hline Study Name & & $\%$ Change $(95 \% \mathrm{Cl})$ & $\%$ Weight \\
\hline Williamson (2013) & - & $6(1,11)$ & 51.39 \\
\hline Busby (2019) & 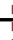 & $5(0,10)$ & 48.61 \\
\hline Overall $($ I-squared $=0.0 \%)$ & 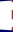 & $6(2,9)$ & 100.00 \\
\hline
\end{tabular}

a Squares indicate study-specific risk estimates (size of the square reflects the study-specific weight); horizontal lines indicate $95 \%$ confidence intervals (Cls); diamond indicates summary estimate with its corresponding $95 \%$ confidence interval. 
Appendix 7: Risk of bias for randomised studies

\begin{tabular}{|c|c|c|c|c|c|c|}
\hline Study ID & Randomisation & Deviation & $\begin{array}{l}\text { Missing } \\
\text { Data }\end{array}$ & $\begin{array}{l}\text { Outcome } \\
\text { Measurement }\end{array}$ & $\begin{array}{l}\text { Reported } \\
\text { Result }\end{array}$ & Overall \\
\hline \multicolumn{7}{|l|}{ Parallel RCT } \\
\hline Robinson (1993) & Low & Low & Low & Low & Low & Low \\
\hline Claman (1994) & Low & Low & Low & Low & Low & Low \\
\hline Robinson (1995) & Low & Low & Low & Low & Low & Low \\
\hline Bentley (1996) & Low & Low & Low & Low & Low & Low \\
\hline Djukanovic (1997) & Low & Low & Low & Low & Low & Low \\
\hline Meijer (1999) & Low & Low & Low & Low & Low & Low \\
\hline Grootendorst (2001) & Low & Low & Low & Low & Low & Low \\
\hline Kurashima (2001) & Low & Low & Low & Low & Low & Low \\
\hline Nguyen (2005) & Low & Low & Low & Low & Low & Low \\
\hline Slats (2006) & Low & Low & Low & Low & Low & Low \\
\hline Dente (2010) & Low & Low & Low & Low & Low & Low \\
\hline Kupczyk (2013) & Low & Low & Low & Low & Low & Low \\
\hline Yick (2013) & Low & Low & Low & Low & Low & Low \\
\hline Fernandes (2014) & Low & Low & Low & Low & Low & Low \\
\hline \multicolumn{7}{|l|}{ Crossover RCT } \\
\hline Jenkins (1988) & Moderate & Low & Low & Low & Low & Moderate \\
\hline Beam (1992) & Low & Serious & Low & Low & Low & Serious \\
\hline Wempe (1992) & Moderate & Low & Low & Low & Low & Moderate \\
\hline Bosman (1994) & Low & Low & Low & Low & Low & Low \\
\hline Wenzel (1994) & Moderate & Serious & Low & Low & Low & Serious \\
\hline Yates (1995) & Moderate & Moderate & Low & Low & Low & Moderate \\
\hline Wilson (1998) & Low & Low & Low & Low & Low & Low \\
\hline Wilson (1999) & Low & Low & Low & Low & Low & Low \\
\hline Liu (2001) & Moderate & Low & Low & Low & Low & Moderate \\
\hline Chaudhuri (2003) & Low & Low & Low & Low & Low & Low \\
\hline Vagaggini (2007) & Low & Low & Low & Low & Low & Low \\
\hline Berthon (2017) & Low & Low & Low & Low & Low & Low \\
\hline
\end{tabular}


Appendix 8: Weighted percentage change in study outcomes following OCS, stratified by risk of bias

\begin{tabular}{|c|c|c|c|c|c|c|}
\hline \multirow{2}{*}{ Outcome } & \multicolumn{3}{|c|}{ Low risk of bias } & \multicolumn{3}{|c|}{ Moderate / high risk of bias } \\
\hline & Studies & \% Change (95\% Cl) & $I^{2}$ & Studies & $\%$ Change $(95 \% \mathrm{Cl})$ & $1^{2}$ \\
\hline FEV $_{1}$ & 18 & $5(4,7)$ & $0.8 \%$ & 35 & $12(9,15)$ & $80.9 \%$ \\
\hline$<60 \%$ predicted & 0 & $\mathrm{~N} / \mathrm{A}$ & N/A & 10 & $19(13,24)$ & $74.0 \%$ \\
\hline $60-70 \%$ predicted & 2 & $8(3,13)$ & $0.0 \%$ & 10 & $10(7,13)$ & $13.0 \%$ \\
\hline $70-80 \%$ predicted & 1 & $9(5,3)$ & N/A & 9 & $8(3,12)$ & $71.9 \%$ \\
\hline$>80 \%$ predicted & 15 & $4(3,6)$ & $0.0 \%$ & 6 & $8(2,15)$ & $88.4 \%$ \\
\hline FVC & 5 & $3(0,6)$ & $28.0 \%$ & 14 & $6(4,9)$ & $75.1 \%$ \\
\hline FeNO & 2 & $-31(-57,-4)$ & $0.0 \%$ & 9 & $-35(-41,-28)$ & $0.0 \%$ \\
\hline Blood Eosinophils & 3 & $-75(-100,-44)$ & $28.9 \%$ & 7 & $-76(-92,-61)$ & $44.5 \%$ \\
\hline Sputum Eosinophils & 5 & $-82(-100,-52)$ & $0.0 \%$ & 5 & $-89(-100,-76)$ & $51.4 \%$ \\
\hline ACQ & 3 & $-20(-32,-9)$ & $0.0 \%$ & 6 & $-23(-37,-9)$ & $52.5 \%$ \\
\hline AQLQ & 0 & $\mathrm{~N} / \mathrm{A}$ & $\mathrm{N} / \mathrm{A}$ & 2 & $6(2,9)$ & $0.0 \%$ \\
\hline
\end{tabular}


Appendix 9: Funnel plot for studies reporting FEV1

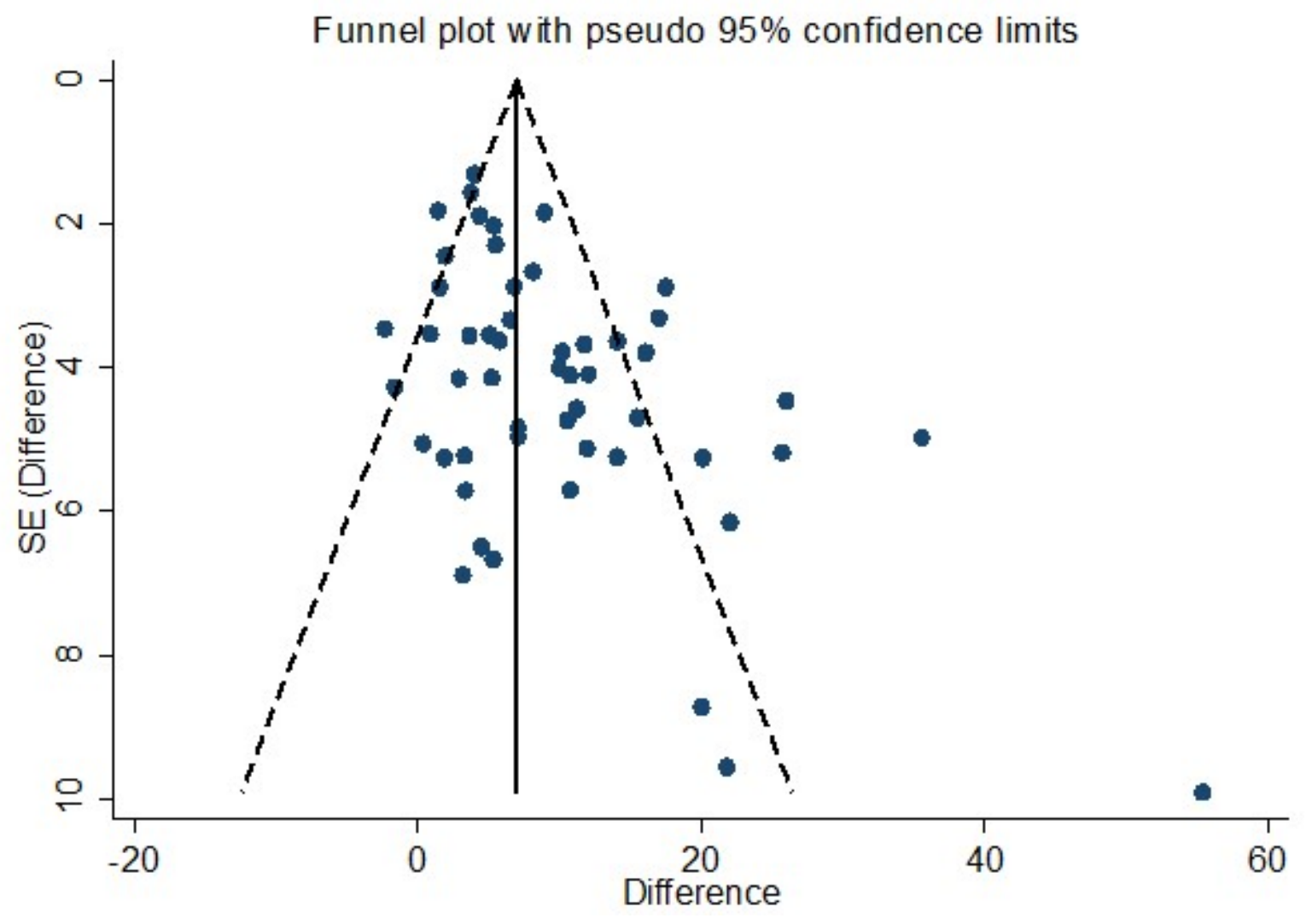

